\title{
Effect of rotating twisted tape on thermo-hydraulic performances of nanofluids in heat-exchanger systems \\ Cong Qi ${ }^{a^{*}}$, Guiqing Wang ${ }^{\text {a }}$, Yuying Yan ${ }^{\text {b*, Siyuan Mei }}{ }^{\text {a }}$, Tao Luo ${ }^{\text {a }}$ \\ ${ }^{a}$ School of Electrical and Power Engineering, China University of Mining and Technology, Xuzhou 221116, China \\ ${ }^{\mathrm{b}}$ Fluids \& Thermal Engineering Research Group, Faculty of Engineering, University of Nottingham, Nottingham NG7 2RD, UK
}

Abstract: Stable $\mathrm{TiO}_{2}-\mathrm{H}_{2} \mathrm{O}$ nanofluids are prepared and their stabilities are studied. An experimental set for studying the heat transfer and flow characteristics of nanofluids is established. Heat transfer and flow characteristics of $\mathrm{TiO}_{2}-\mathrm{H}_{2} \mathrm{O}$ nanofluids in a circular tube with rotating and static built-in twisted tapes are experimentally investigated and compared. An innovative performance evaluation plot of exergy efficiency is developed and the exergy efficiency of tube with rotating and static built-in twisted tapes filled with nanofluids is analyzed in this paper. The results indicate that the combination of rotating built-in twisted tape and $\mathrm{TiO}_{2}-\mathrm{H}_{2} \mathrm{O}$ nanofluids shows an excellent enhancement in heat transfer, which can increase the heat transfer by $101.6 \%$ compared with that of in a circular tube. The effects of nanoparticle mass fractions $(\omega=0.1 \%, 0.3 \%$ and $0.5 \%)$ and Reynolds numbers $(R e=600-7000)$ on the heat transfer and flow characteristics of $\mathrm{TiO}_{2}-\mathrm{H}_{2} \mathrm{O}$ nanofluids are discussed. It is found that there is a critical Reynolds number $(R e=4500)$ for the maximum value of relative heat transfer enhancement ratio. The comprehensive performance of the experimental system is analyzed. It can be found that the comprehensive performance index of the experimental system firstly increases and then reduces with Reynolds number, and it can reach 1.519 at best. However, for the

*Correspondence author.

E-mail: qicong@cumt.edu.cn (C. Qi), gqwang@cumt.edu.cn (G. Wang), yuying.yan@nottingham.ac.uk (Y. Yan), meisiyuan@cumt.edu.cn (S. Mei), luotao@cumt.edu.cn (T. Luo) 

nanofluids deteriorates the exergy efficiency. Also, it can be found that the exergy efficiency of the circular tube with twisted tape is greater than that of circular tube under the same pumping power and pressure drop, but it shows deterioration under

29 the same mass flow rate.

30 Keywords: Nanofluids; Rotating twisted tape; Heat transfer enhancement;

31 Nanoparticle mass fraction; Exergy efficiency 
cross-sectional area, $\mathrm{m}^{2}$ intercept of straight line coefficient in equation heat capacity of nanofluids, $79 R e$ $\mathrm{J} \cdot \mathrm{kg}^{-1} \cdot \mathrm{K}^{-1}$

$80 T_{0}$ heat capacity of base fluid, $81 T(\mathrm{x})$ $\mathrm{J} \cdot \mathrm{kg}^{-1} \cdot \mathrm{K}^{-1}$

$82 T \mathrm{w}(\mathrm{x})$ heat capacity of nanoparticles, $83 \quad T_{\text {out }}$ $\mathrm{J} \cdot \mathrm{kg}^{-1} \cdot \mathrm{K}^{-1}$

$84 T_{\text {in }}$ the ratio of heat transfer rate $85 T_{\mathrm{f}}$ between enhanced and 86 reference surfaces under $87 T_{\mathrm{w}}{ }^{*}$ identical pumping power 88 the ratio of heat transfer rate 89 between enhanced and 90 reference surfaces over the ratio $91 T_{\mathrm{w}}$ of friction factor between 92 enhanced and reference 93 surfaces under identical flow 94

$95 \omega$

$$
\text { rate }
$$

the ratio of heat transfer rate $96 \rho$ between enhanced reference surfaces and $97 \rho_{\mathrm{pb}}$ identical pressure drop under $98 \rho_{\mathrm{pp}}$ equivalent diameter, $\mathrm{m}$ $99 \lambda$

$$
\text { relative heat }
$$
enhancement ratio exergy loss, J heat transfer exergy, $\mathbf{J}$ 100
transfeit $01 \zeta$ 102 103 Subscripts frictional resistance coefficient 105 in convective heat transferl06 out coefficient, $\mathrm{W} \cdot \mathrm{m}^{-2} \cdot \mathrm{K}^{-1} \quad 1070$ thermal conductivity ofl $08 \mathrm{e}$ nanofluids, $\mathrm{W} \cdot \mathrm{m}^{-1} \cdot \mathrm{K}^{-1}$

$109 \mathrm{p}$

slope of straight line $110 \mathrm{pb}$
Heat flux density, $\mathrm{W} \cdot \mathrm{m}^{-1}$

mass flow rate, $\mathrm{kg} \cdot \mathrm{s}^{-1}$

outside-radius of tube, $\mathrm{m}$ inner-radius of tube, $\mathrm{m}$

Reynolds number temperature of ambient, $\mathrm{K}$ temperature of fluid, $\mathrm{K}$ temperature of wall, $\mathrm{K}$ outlet temperature of tube, $\mathrm{K}$ inlet temperature of tube, $\mathrm{K}$ average temperature of nanofluids, $\mathrm{K}$

outside surface temperature of tube, $\mathrm{K}$

temperature of T-type thermocouples, $\mathrm{K}$

inside surface temperature of tube, $\mathrm{K}$

velocity of nanofluids, $\mathrm{m} \cdot \mathrm{s}^{-1}$

\section{Greek symbols}

mass fraction, $\%$

density of nanofluids, $\mathrm{kg} \cdot \mathrm{m}^{-3}$

density of base fluid, $\mathrm{kg} \cdot \mathrm{m}^{-3}$

density of nanoparticle, $\mathrm{kg} \cdot \mathrm{m}^{-3}$ thermal conductivity of tube, $\mathrm{W} \cdot \mathrm{m}^{-1} \cdot \mathrm{K}^{-1}$

comprehensive performance index

exponent in equation

import

outport

circular tube

enhanced tube

nanofluids

base fluid

nanoparticle

under the same pumping power

under the same Reynolds number

under the same mass flow rate under the same pressure drop wall 


\section{Introduction}

With the development of science and technology, the thermal load of the heat exchanger gradually increases. Also, the traditional structure of heat exchanger and working fluid cannot meet the requirement of heat exchanger in a limited heat exchange area. Hence, the heat transfer enhancement technology needs to be improved.

Improving the thermal conductivity of the working medium is one way to enhance the heat transfer. Nanofluids, as a new type of high efficient energy transport medium, have great application values in many fields. Huang et al. [1] added the $\mathrm{Au} @ \mathrm{TiO}_{2}$ core-shell nanoparticles into the clean water. It was found that the core-shell structure can improve the photo-thermal conversion efficiency and the evaporation of seawater. Many scholars applied nanofluids to solar photothermal conversion. Chen et al. [2] studied the solar absorption performances of different core-shell nanoparticles. It was found that the core-shell ratios and mixing ratios of nanofluids are two key factors for improving the absorption of solar energy efficiency.

Wang et al. [3] applied CNT nanofluids with different concentrations to direct solar steam generation and found that the evaporation efficiency can reach $45 \%$ under a solar illumination power of 10 Sun when the concentration of CNT nanofluids is 0.001904 vol.\%. Liu et al. $[4,5]$ proposed the principle of photonic nanofluids and studied the solar-thermal conversion efficiencies of different types of nanospheres.

Xuan et al. [6] presented a procedure for preparing nanofluids and proposed a theoretical model to calculate the heat transfer performance of nanofluids. Oztop et al. 
140 [7] researched the natural convection of nanofluids in rectangular enclosures by 141 numerical simulation. It was found that the heat transfer enhancement of low aspect 142 ratio is much better than that of high aspect ratio. Heris et al. [8] investigated the heat 143 transfer characteristic of $\mathrm{Al}_{2} \mathrm{O}_{3}$-water nanofluids in a circular tube and found that the 144 heat transfer coefficient increases with nanoparticle concentration and Peclet number. $145 \mathrm{Li}$ et al. $[9,10]$ measured the thermophysical properties of nanofluids and found that metal nanoparticles can increase the thermal conductivity and viscosity of the fluid. considering the effect of particle disaggregation. It was found that nanofluids behaved as Newtonian fluid when the nanoparticles were evenly dispersed in the base fluid. and proposed an empirical equation to calculate the concentration of nanoparticles in a centre in the pipe and it has a maximum value near the pipe wall. Sheremet et al. [13] studied the effects of boundary temperature oscillating frequency on the natural convection of a square cavity filled with alumina-water nanofluids and found that Nusselt number increases with the oscillating frequency of boundary temperature. In addition, Sheremet et al. [14] numerically investigated the natural convection of a triangular cavity filled with micropolar fluid. It was found that the average Nusselt number and fluid flow rate all decrease with the vortex viscosity parameter. Also, Sheremet et al. [15] analyzed the natural convection of $\mathrm{Cu}$-water nanofluids in a cavity and found that heat transfer decreases with Hartmann number. Sheikholeslami 
et al. [16] researched the natural convection of magnetohydrodynamic nanofluids and found that Nusselt number increases with Darcy number, supplied voltage and Rayleigh number. Sheikholeslami et al. [17] also studied the effect of uniform magnetic field on natural convection of nanofluids in a porous media with sinusoidal hot cylinder and found that temperature gradient decreases with Hartmann number. In addition, Sheikholeslami et al. [18] investigated the effect of nanoparticle shape on heat transfer by means of CVFEM. It was found that Platelet shaped nanoparticles has the highest heat transfer performance.

Rudyak et al. [19] conducted an experiment on aluminum lithium-liquid argon nanofluids with different nanoparticle sizes. It was found that the viscosity of nanofluids increases with the decreasing nanoparticle size. Pendyala et al. [20] and Ilyas et al. [21] applied nanofluids to transformers and obtained that adding CNTs and graphite nanoparticles with different sizes can significantly improve the thermal conductivity of fluid. Kouloulias et al. [22] studied the precipitation of $\mathrm{Al}_{2} \mathrm{O}_{3}-\mathrm{H}_{2} \mathrm{O}$ nanofluids and analyzed the natural convection heat transfer characteristics of nanofluids. It was found that Nusselt number decreases with the nanoparticle concentration. Qi et al. [23] conducted an experiment on different rotation angles of enclosure filled with $\mathrm{TiO}_{2}$-water nanofluids. It was found that the enclosure with rotation angle $\alpha=0^{\circ}$ has the highest Nusselt number. Qi et al. [24, 25] studied the effects of nanoparticle radius on the natural convection heat transfer by numerical simulation and found that Nusselt number decreases with the increasing nanoparticle radius. Also, Qi et al. [26] investigated the natural convection heat transfer of 
enclosures with different aspect ratios and found that Nusselt number increases with the aspect ratio of the enclosure. Qi et al. [27] also researched the boiling heat transfer of $\mathrm{TiO}_{2}$-water nanofluids. The results showed that $\mathrm{TiO}_{2}$-water nanofluids enhance the heat transfer coefficient by $77.7 \%$ at best compared with water. In addition, Qi et al. [28] introduced nanofluids as a working medium to cool the CPU. It was found that $\mathrm{Al}_{2} \mathrm{O}_{3}-\mathrm{H}_{2} \mathrm{O}$ and $\mathrm{TiO}_{2}-\mathrm{H}_{2} \mathrm{O}$ nanofluids can reduce the temperature of $\mathrm{CPU}$ by $23.2 \%$ and $14.9 \%$ at best compared with based fluid (water) respectively.

Above studies show that nanofluids with a certain mass fraction can play a role in enhancing heat transfer. In order to improve the heat transfer of heat exchanger, enhanced tubes are used instead of smooth tube. In addition, researchers have done some work on the heat transfer of nanofluids in enhanced tubes.

Shahril et al. [29] studied the heat transfer performance of $\mathrm{Cu}-\mathrm{H}_{2} \mathrm{O}$ nanofluids in a concentric tube. It was found that the thermal conductivity can be improved by $60 \%$ when the volume fraction of nanoparticles reaches $2 \%$. Sun et al. [30, 31] researched the flow and heat transfer of different types of nanofluids in the built-in twisted belt external thread tubes. The results presented that the coupled heat transfer between $\mathrm{Cu}-\mathrm{H}_{2} \mathrm{O}$ nanofluids and the built-in belt can improve the heat transfer by $50.32 \%$. Naphon et al. [32] experimentally studied the flow and heat transfer characteristics of $\mathrm{TiO}_{2}$-water nanofluids in a horizontal spirally coiled pipe. The results presented that the heat transfer can be improved by $34.07 \%$ when the volume fraction of nanofluids is $0.05 \%$. Qi et al. investigated the heat transfer characteristics of nanofluids in a corrugated tube [33], a spirally fluted tube [34] and a horizontal elliptical tube [35] 
respectively. It was found that the heat transfer of enhanced heat tubes can be greatly improved at the cost of little increase in flow resistance compared with that of conventional tubes. Sundar et al. [36] experimentally studied the heat transfer of $\mathrm{CNT}-\mathrm{Fe}_{3} \mathrm{O}_{4} /$ water hybrid nanofluids in a built-in twisted tape tube. The study found that the built-in twisted tape tube can enhance the Nusselt number by $42.51 \%$.

The first law of thermodynamics is about the quantity of energy, but the second law of thermodynamics is about the quality of energy. Therefore, the second law of thermodynamics is more suitable for evaluation of the heat exchanger heat transfer process under certain conditions. Based on the second law of thermodynamics, scholars conducted many researches on entropy and exergy.

Khalkhali et al. [37] studied the entropy production of heat pipes, and found that the entropy production is caused by the temperature difference of the hot and cold fluids, the flow friction and the evaporation temperature/pressure drop along the heat pipe. Haddad et al. [38] obtained the distribution of entropy production based on the entropy production equation and studied the effects of different thermal boundary conditions on heat, viscosity and total entropy production. It was found that the entropy production and the Reynolds number are inversely proportional to the dimensionless inlet temperature and proportional to the radius ratio. Ploumen et al. [39] studied the exergy efficiency of three different types of turbines and pointed out the main components of the exergy loss. The results showed that the exergy loss of the combustion chamber accounted for $22 \%$. Replacing the combustion chamber with a fuel tank can reduce the exergy loss by $10 \%$. Gutowski et al. [40] analyzed the energy 
conversion process in manufacturing, and summarized the thermodynamic data of the thermal efficiency and exergy efficiency of materials in the manufacturing process by energy analysis and exergy analysis. Modarresi [41] studied the process of producing bio-ethanol, bio-methane, heat and power from wheat straw using exergy analysis. It was found that the bio-ethanol process has the highest exergy efficiency.

It can be seen from above studies that researchers have made great contributions to the heat transfer enhancement of nanofluids. However, there is little research on the effects of the rotating built-in twisted tape on heat transfer and flow characteristics of tube filled with $\mathrm{TiO}_{2}-\mathrm{H}_{2} \mathrm{O}$ nanofluids, also, there is no an exergy efficiency evaluation criteria. In this paper, heat transfer and flow characteristics of $\mathrm{TiO}_{2}-\mathrm{H}_{2} \mathrm{O}$ nanofluids in a circular tube with rotating and static built-in twisted tapes are experimentally investigated and compared. The influences of nanoparticle mass fraction and Reynolds number on the comprehensive thermo-hydraulic performances are analyzed. The main innovations are as follows: (1) Unlike the thermo-hydraulic comprehensive evaluation frequently adopted by researchers, exergy-resistance comprehensive evaluation instead of it is analyzed, and an innovative performance evaluation plot for exergy efficiency is developed; (2) Unlike the studies of the effects of static built-in thermo-hydraulic performance, the effects of rotating instead of static twisted tapes on exergy-resistance performance are investigated.

\section{Method}

2.1 Nanofluids preparation and stability study

In this paper, $\mathrm{TiO}_{2}-\mathrm{H}_{2} \mathrm{O}$ nanofluids with different mass fractions $(\omega=0.1 \%, 0.3 \%$ 
and $0.5 \%$ ) are prepared by a two-step method. Firstly, nanoparticles are added into the base fluid (deionized water), then some dispersant and $\mathrm{NaOH}$ are added to prevent nanoparticles from gathering or precipitating, finally, the nanofluids are oscillated by ultrasonic about 40 minutes to make the nanoparticles distribute uniformly in the base fluid. The preparation process is shown in Figure 1. Table 1 shows the information of materials and instruments used in the experiment.

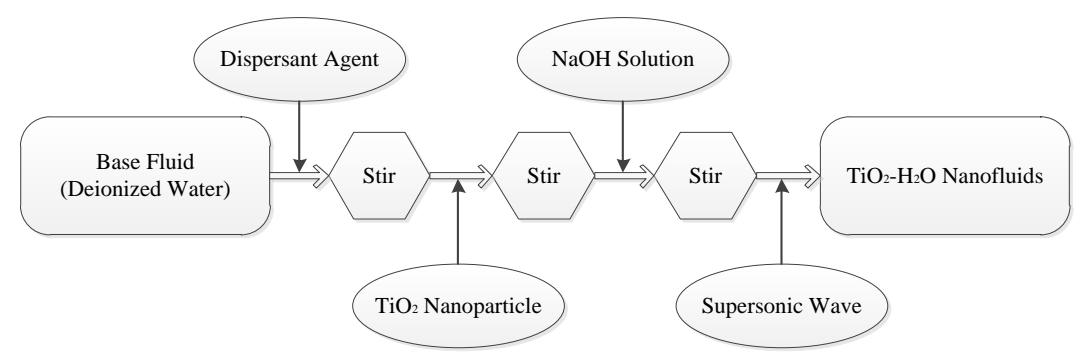

Figure 1 Preparation procedure of $\mathrm{TiO}_{2}-\mathrm{H}_{2} \mathrm{O}$ nanofluids by a two-step method In order to observe the microscopic structure of the $\mathrm{TiO}_{2}$ nanoparticles, the transmission electron microscope (TEM) photographs of nanoparticles have been shown in Figure 2.

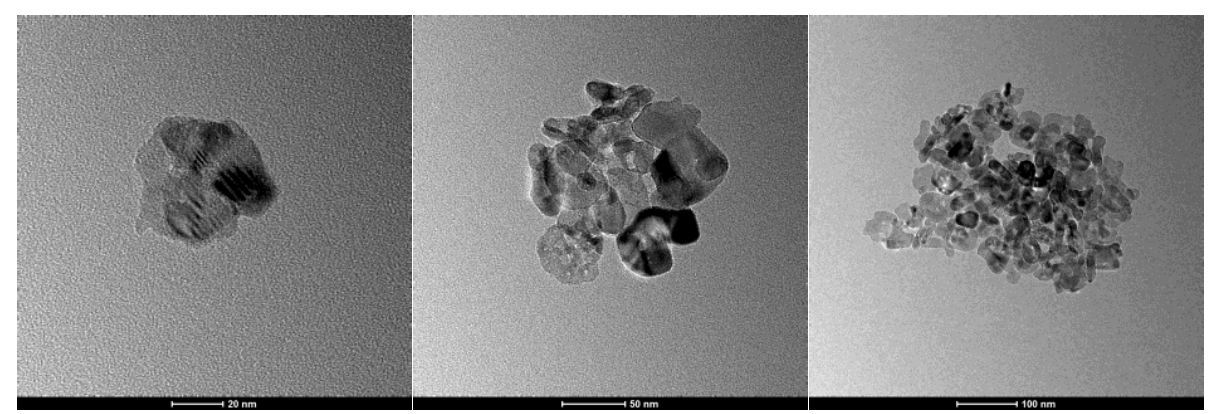

(a)

(b)

(c)

Figure 2 TEM images of $\mathrm{TiO}_{2}$ nanoparticles at different magnifications, (a) 20nm; (b) $\longmapsto 50 \mathrm{~nm}$; (c) $\longmapsto 100 \mathrm{~nm}$ 
Table 1 Information of materials and instruments

\begin{tabular}{|c|c|c|}
\hline $\begin{array}{l}\text { Materials and } \\
\text { instruments }\end{array}$ & Manufacturer & Properties \\
\hline $\begin{array}{c}\mathrm{TiO}_{2} \\
\text { nanoparticles }\end{array}$ & $\begin{array}{l}\text { Nanjing Tansail } \\
\text { Advanced Materials } \\
\text { Co., Ltd. }\end{array}$ & $\begin{array}{c}\text { Type: TTP-A10; } \\
\text { Crystal form: anatase; } \\
\text { Particle diameter:10nm }\end{array}$ \\
\hline $\begin{array}{c}\text { Base fluid } \\
\text { (deionized water) }\end{array}$ & $\begin{array}{l}\text { Prepared by a } \\
\text { ultrapure water } \\
\text { device }\end{array}$ & $\begin{array}{c}\text { Resistivity: } \\
16-18.2 \mathrm{M} \Omega \cdot \mathrm{cm} @ 25^{\circ} \mathrm{C}\end{array}$ \\
\hline $\begin{array}{l}\text { Ultrapure } \\
\text { water device }\end{array}$ & $\begin{array}{l}\text { Nanjing Yeap } \\
\text { Esselte Technology } \\
\text { Development Co., } \\
\text { Ltd. }\end{array}$ & Type: EPED-E2-10TJ \\
\hline \multirow[b]{2}{*}{$\begin{array}{c}\text { Ultrasonic } \\
\text { oscillation device }\end{array}$} & $\begin{array}{c}\text { Nanjing Tansail } \\
\text { Advanced Materials } \\
\text { Co., Ltd. }\end{array}$ & $\begin{array}{c}\text { Type: TDL-ND1; } \\
\text { Element: } \\
\text { macromolecule polymers; } \\
\text { Scope of application: } \\
\text { water or solvent (base fluid) }\end{array}$ \\
\hline & $\begin{array}{l}\text { Shenzhen Jeken } \\
\text { Ultrasonic } \\
\text { Technology Co., Ltd. }\end{array}$ & $\begin{array}{l}\text { Type: PS-100A; } \\
\text { Ultrasonic frequency: } \\
40000 \mathrm{HZ}\end{array}$ \\
\hline $\begin{array}{c}\text { Magnetic } \\
\text { stirring apparatus }\end{array}$ & $\begin{array}{l}\text { Shanghai } \\
\text { Meiyingpu } \\
\text { Instrument } \\
\text { Manufacturing Co., } \\
\text { Ltd. }\end{array}$ & $\begin{array}{l}\text { Type: MYP11-2 } \\
\text { Rotate speed: } \\
\text { 50 1500r/min }\end{array}$ \\
\hline $\begin{array}{l}\text { Pressure } \\
\text { transmitter }\end{array}$ & $\begin{array}{c}\text { Chongqing } \\
\text { Weian } \\
\text { Instrument } \\
\text { Manufacturing Co., } \\
\text { Ltd. }\end{array}$ & $\begin{array}{c}\text { Type: SSTCC; } \\
\text { Precision: } 0.5 \%\end{array}$ \\
\hline
\end{tabular}

$27310 \mathrm{~nm}$. In addition, it can be seen that the nanoparticles have been gathered together, 
which can cause nanoparticles to precipitate in the water easily.

With a relatively low mass concentration, nanofluids can show a better stability. In addition, the comprehensive performance indexes $\xi$ increases with Reynolds number when $\omega \leqslant 0.3 \%$ but decreases with Reynolds number when $\omega>0.3 \%$, hence only one mass concentration $\omega=0.5 \%$ after $\omega=0.3 \%$ is chosen in this manuscript. Finally, three nanoparticle mass fractions $(\omega=0.1 \%, 0.3 \%$ and $0.5 \%)$ are adopted in this experiment.

In order to ensure the stability of the prepared nanofluids, it is analyzed by sedimentation observation method in this paper. The changes of $\mathrm{TiO}_{2}-\mathrm{H}_{2} \mathrm{O}$ nanofluids with different mass fractions $(\omega=0.1 \%, 0.3 \%$ and $0.5 \%)$ before and after standing some time are shown in Figure 3. It can be observed from Figure 3 that nanofluids with different mass fractions do not show any obvious agglomeration or precipitation after standing for 7 days, which proves that the nanofluids prepared in this paper can meet the experimental requirement.

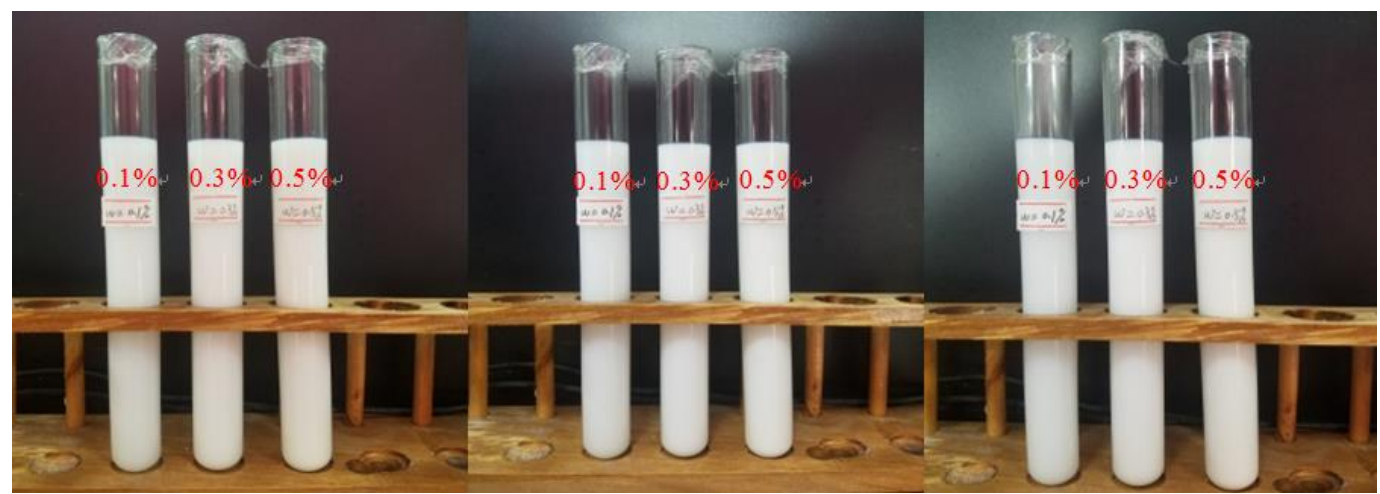

(a)

(b)

(c)

Figure 3 Nanofluids at different times, (a) before laying up; (b) laying up for 3 days; (c) laying up for 7 days

In our previous published literature [33], thermophysical properties of $\mathrm{TiO}_{2}$-water nanofluids have been experimentally measured, which are shown in 

and shear rate $\gamma$ is line, which matches the characteristic of Newtonian fluid. Hence, $\mathrm{TiO}_{2}$-water nanofluids can be approximately regarded as a kind of Newtonian fluid, and the effects of non-Newtonian can be ignored. The other details of explanation for Figure 4 (b-d) can be found in our previous published literature [33].

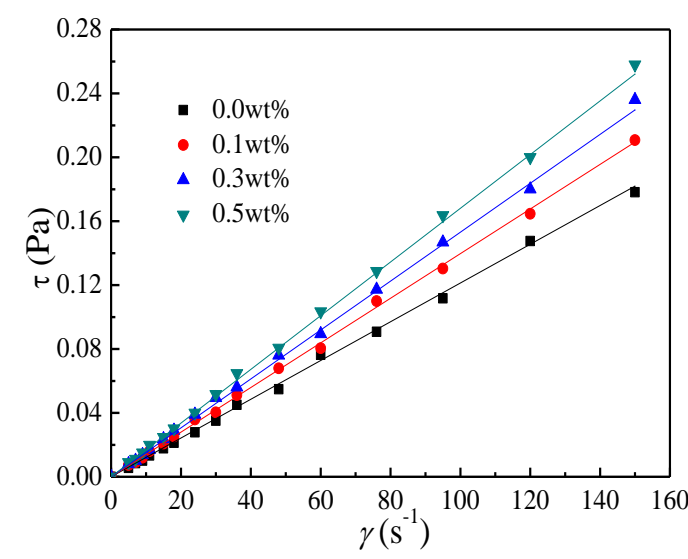

(a)

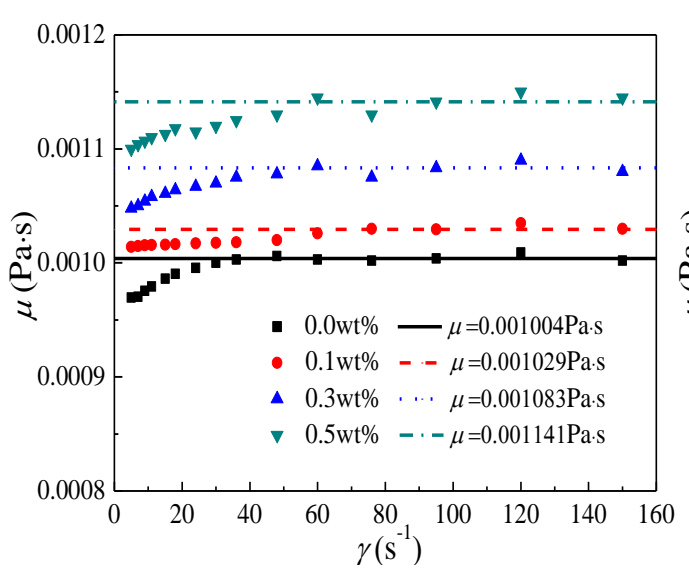

(c)

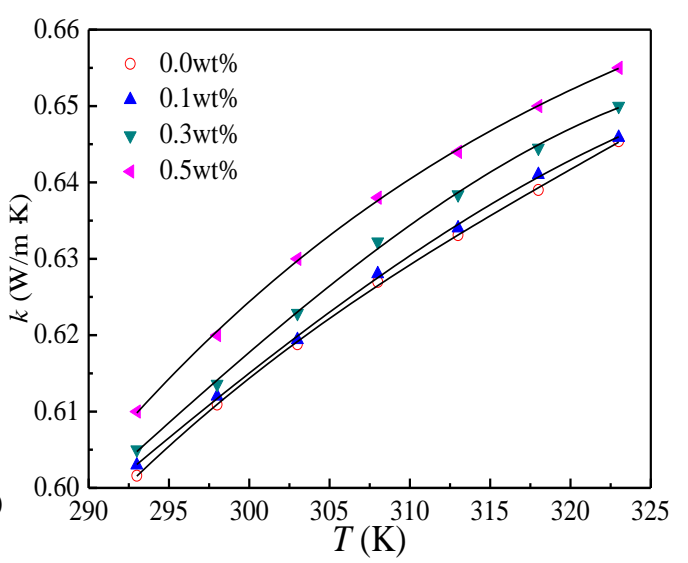

(b)

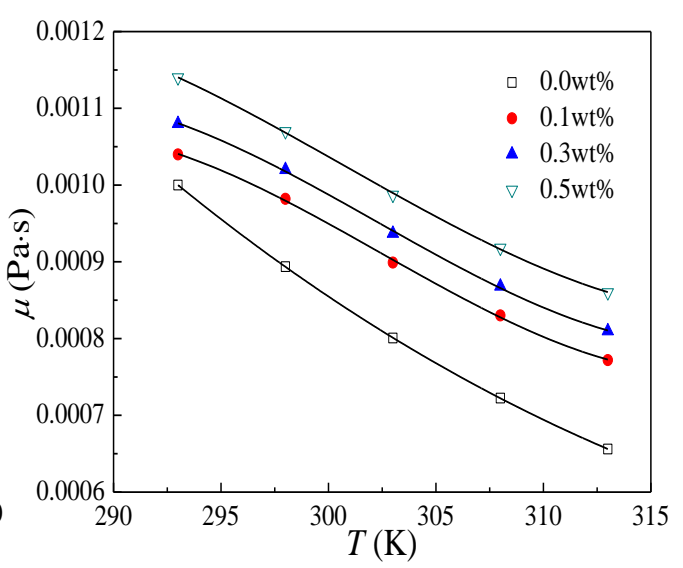

(d)

Figure 4 Thermophysical properties of $\mathrm{TiO}_{2}$-water nanofluids (a) Newtonian-fluids characteristics at $T_{\mathrm{f}}=293 \mathrm{~K}$; (b) thermal conductivities; (c) viscosity changes with shear rates at $T_{\mathrm{f}}=293 \mathrm{~K}$; (d) viscosity changes with temperatures [33]

2.2 Experimental system

As shown in Figure 5, the flow and heat transfer experiment system is established in this paper. Fluid flow is mainly powered by a submersible pump, and the flow is regulated by a valve. A nickel flat heating wire is evenly winded around 
311 the tube wall to ensure the tube wall to be heated uniformly, and the power is supplied 312 by a DC-power. A layer of mica flake is covered on the periphery of the tube wall to 313 achieve insulation between the tube wall and the heating wire. A low temperature 314 thermostat is used to control the inlet temperature. In order to reduce heat loss, 315 insulation material is wrapped around the tube wall. minute (RPM). The detail sizes of the stainless steel circular tube are as follows: inner section $1000 \mathrm{~mm}$ is used as the test section. The structure of the twisted tape is shown 


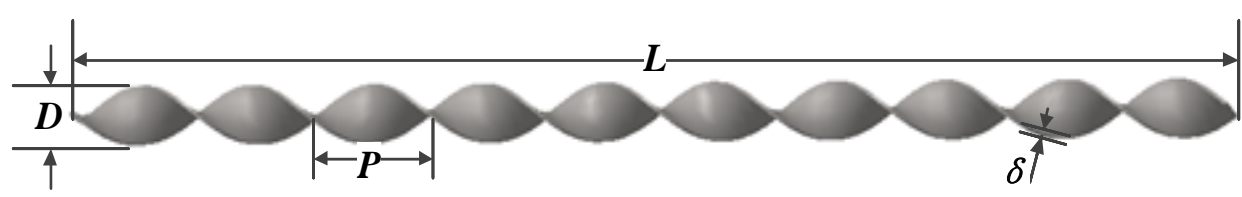

Figure 6 Structure of the twisted tape Table 2 Parameters of the twisted tape

\begin{tabular}{ccccc}
\hline Parameters & length $(L)$ & pitch $(P)$ & width $(D)$ & thickness $(\delta)$ \\
\hline Size $(\mathrm{mm})$ & 1600 & 100 & 16 & 2 \\
\hline
\end{tabular}

Ten T-type thermocouples are placed on the wall of tube to measure the average wall temperature. Two armored thermocouples are placed at the import and export of the experimental tube respectively to measure the import and export temperatures of the working fluid. The details of thermocouple arrangement are shown in Figure 7. In order to reduce the influences of inlet effect, the first and the last thermocouples are placed $200 \mathrm{~mm}$ away from the inlet and outlet. In addition to the temperature, the pressure drop of the test tube is measured by a differential pressure instrument. Because the heat exchanger in reality runs under equilibrium state most of the time, in order to investigate the flow and heat transfer of fluid in the heat exchanger, pressure drop measurements are conducted when the flow and temperature field all reach an equilibrium state.

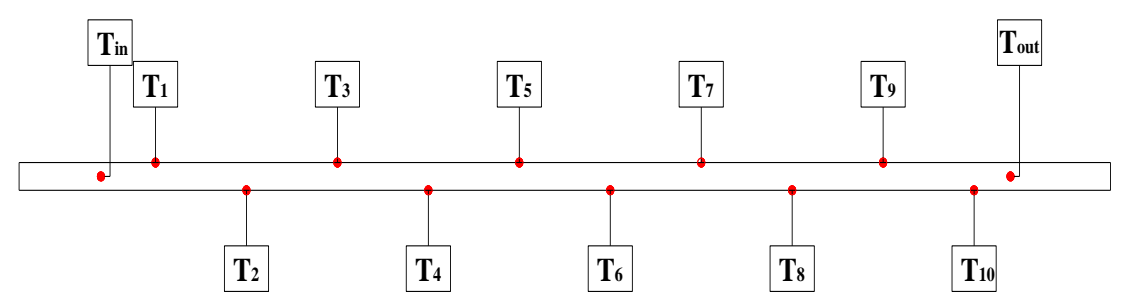

Figure 7 Schematic diagram of thermocouple distribution

\subsection{Establishment of an exergy efficiency evaluation criteria}

The physical model of heat transfer process shown in Figure 8 is established to deduce the exergy efficiency equation. In order to simplify the heat transfer process, 
some assumptions are adopted as follows: heat transfer and flow process are steady state; the thermophysical properties of fluid are constant; the axial heat loss is ignored.

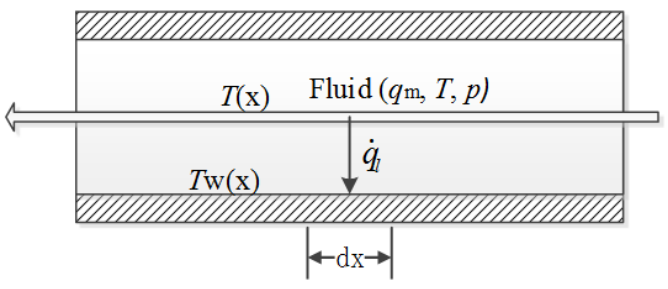

Figure 8 Physical model of heat transfer process

The formula of exergy loss caused by heat transfer is shown as follows [42]:

$$
\Delta \dot{E}_{1}=\frac{T_{0}}{T(x)}\left[\frac{q_{\mathrm{m}}{ }^{3} f}{\rho^{2} 2 A^{2} d}\right] d x+T_{0} \dot{q}_{l} d x\left[\frac{T(x)-T w(x)}{T(x) T w(x)}\right]
$$

The formula of exergy caused by heat transfer is shown as follows:

$$
\Delta \dot{E}_{\mathrm{x} Q}=\dot{q}_{l} d x\left[1-\frac{T_{0}}{T(x)}\right]
$$

The formula of exergy efficiency is shown as follows:

$$
\eta=\frac{\Delta \dot{E}_{\mathrm{x} Q}-\Delta \dot{E}_{1}}{\Delta \dot{E}_{\mathrm{x} Q}}
$$

Substituting Eq. (3) into Eq. (1), the formula of exergy efficiency becomes:

$$
\eta=1-\frac{\frac{T(x)-T w(x)}{T w(x)}+\frac{8 q_{\mathrm{m}}{ }^{3} f}{\pi^{2} \rho^{2} d^{5} \dot{q}_{l}}}{\frac{T(x)}{T_{0}}-1}
$$

The exergy efficiency equation is based on the following assumptions: (1) Equivalent diameter of enhanced tube is the same as that of circular tube; (2) Heat transfer area of enhanced tube is the same as that of circular tube; (3) Temperature of the fluid in the tube and temperature of tube wall are constant; (4) The thermophysical properties of fluid are constant; (5) Dimensionless parameter of enhanced tube is the 
same as that of circular tube. enhanced:

According to the Eq. (3), it is defined as follows when the exergy efficiency is

$$
\frac{\eta_{\mathrm{e}}}{\eta_{0}}>1
$$

Based on above assumptions, it can be obtained that:

Substituting Eq. (6) and (7) into Eq. (5), the formula becomes:

$$
\left(\frac{8 q_{\mathrm{m}}^{3} f}{\pi^{2} \rho^{2} d^{5} \dot{q}_{l}}\right)_{\mathrm{e}} /\left(\frac{8 q_{\mathrm{m}}^{3} f}{\pi^{2} \rho^{2} d^{5} \dot{q}_{l}}\right)_{0}<1
$$

Eq. (8) can be simplified as follows:

$$
\left(\frac{q_{\mathrm{m}}{ }^{3} f}{Q}\right)_{\mathrm{e}} /\left(\frac{q_{\mathrm{m}}{ }^{3} f}{Q}\right)_{0}<1
$$

When the pumping power is same, it can be known from the literature [43]:

$$
\frac{P_{\mathrm{e}}}{P_{0}}=\frac{\left(A_{\mathrm{c}} \cdot u \cdot \Delta p\right)_{\mathrm{e}}}{\left(A_{\mathrm{c}} \cdot u \cdot \Delta p\right)_{0}}=\frac{\left(A_{\mathrm{c}} \cdot V \cdot f \cdot l \cdot \rho \cdot u^{2} / d\right)_{\mathrm{e}}}{\left(A_{\mathrm{c}} \cdot V \cdot f \cdot l \cdot \rho \cdot u^{2} / d\right)_{0}}
$$

Based on the assumptions, it can be simplified as follows:

$$
\frac{\left(A_{\mathrm{c}} \cdot l \cdot \rho \cdot / d\right)_{\mathrm{e}}}{\left(A_{\mathrm{c}} \cdot l \cdot \rho \cdot / d\right)_{0}}=1
$$

Substituting Eq. (11) into Eq. (10), the formula becomes:

$$
\frac{P_{\mathrm{e}}}{P_{0}}=\frac{\left(f \cdot u^{3}\right)_{\mathrm{e}}}{\left(f \cdot u^{3}\right)_{0}}
$$

Based on the formula of mass flow rate, it can be obtained that: 


$$
\frac{\left(q_{\mathrm{m}}^{3}\right)_{\mathrm{e}}}{\left(q_{\mathrm{m}}^{3}\right)_{0}}=\frac{\left(\frac{\pi \cdot d^{2}}{4} \cdot u \cdot \rho\right)_{\mathrm{e}}^{3}}{\left(\frac{\pi \cdot d^{2}}{4} \cdot u \cdot \rho\right)_{0}^{3}}=\frac{\left(u^{3}\right)_{\mathrm{e}}}{\left(u^{3}\right)_{0}}
$$

Substituting Eq. (13) into Eq. (12), the formula becomes:

$$
\frac{P_{\mathrm{e}}}{P_{0}}=\frac{\left(f \cdot u^{3}\right)_{\mathrm{e}}}{\left(f \cdot u^{3}\right)_{0}}=\frac{\left(f \cdot q_{\mathrm{m}}^{3}\right)_{\mathrm{e}}}{\left(f \cdot q_{\mathrm{m}}^{3}\right)_{0}}
$$

becomes:

$$
\frac{Q_{\mathrm{e}}}{Q_{0}}>1
$$

It can be known from the literature [43]:

$$
\frac{Q_{\mathrm{e}}}{Q_{0}}=\left(\frac{N u_{\mathrm{e}}}{N u_{0}}\right)_{R e} /\left(\frac{f_{\mathrm{e}}}{f_{0}}\right)_{R e}^{\frac{\mathrm{m}_{2}}{3+\mathrm{m}_{1}}}
$$

Substituting Eq. (16) into Eq. (15), the formula becomes:

$$
\left(\frac{N u_{\mathrm{e}}}{N u_{0}}\right)_{R e} /\left(\frac{f_{\mathrm{e}}}{f_{0}}\right)_{R e}^{\frac{\mathrm{m}_{2}}{3+\mathrm{m}_{1}}}>1
$$

When the pressure drop is same, it can be known from the literature [43]:

$$
\frac{\Delta p_{\mathrm{e}}}{\Delta p_{0}}=\frac{\left(f \cdot l / d \cdot \rho \cdot u^{2} / 2\right)_{\mathrm{e}}}{\left(f \cdot l / d \cdot \rho \cdot u^{2} / 2\right)_{0}}=\frac{\left(f \cdot u^{2}\right)_{\mathrm{e}}}{\left(f \cdot u^{2}\right)_{0}}=\frac{\left(f \cdot q_{\mathrm{m}}\right)_{\mathrm{e}}}{\left(f \cdot q_{\mathrm{m}}\right)_{0}}
$$

Substituting Eq. (18) into Eq. (9), the formula becomes:

$$
\left(\frac{q_{\mathrm{m}}}{Q}\right)_{\mathrm{e}} /\left(\frac{q_{\mathrm{m}}}{Q}\right)_{0}<1
$$

It can be known from Eq. (13):

$$
\frac{\left(q_{\mathrm{m}}\right)_{\mathrm{e}}}{\left(q_{\mathrm{m}}\right)_{0}}=\frac{u_{\mathrm{e}}}{u_{0}}
$$

According to the definition of Reynolds number, it is easy to know that: 


$$
\frac{\operatorname{Re}_{\mathrm{e}}}{\operatorname{Re}_{0}}=\frac{\left(\frac{u d}{v}\right)_{\mathrm{e}}}{\left(\frac{u d}{v}\right)_{0}}=\frac{u_{\mathrm{e}}}{u_{0}}
$$

Substituting Eq. (21) into Eq. (20), the formula becomes:

$$
\frac{\left(q_{\mathrm{m}}\right)_{\mathrm{e}}}{\left(q_{\mathrm{m}}\right)_{0}}=\frac{R e_{\mathrm{e}}}{R e_{0}}
$$

Substituting Eq. (22) into Eq. (19), the formula becomes:

$$
\left(\frac{Q_{\mathrm{e}}}{Q_{0}}\right) /\left(\frac{R e_{\mathrm{e}}}{R e_{0}}\right)>1
$$

When the pressure drop is the same, it can be known from the literature [43]:

$$
\begin{gathered}
\frac{Q_{\mathrm{e}}}{Q_{0}}=\left(\frac{N u_{\mathrm{e}}}{N u_{0}}\right)_{R e} /\left(\frac{f_{\mathrm{e}}}{f_{0}}\right)_{R e}^{\frac{\mathrm{m}_{2}}{2+\mathrm{m}_{1}}} \\
\frac{R e_{\mathrm{e}}}{R e_{0}}=\left(\frac{f_{\mathrm{e}}}{f_{0}}\right)_{R e}^{\frac{-1}{2+\mathrm{m}_{1}}}
\end{gathered}
$$

Substituting Eq. (24) and (25) into Eq. (23), the formula becomes:

$$
\left(\frac{N u_{\mathrm{e}}}{N u_{0}}\right)_{R e} /\left(\frac{f_{\mathrm{e}}}{f_{0}}\right)_{R e}^{\frac{\mathrm{m}_{2}-1}{2+\mathrm{m}_{1}}}>1
$$

According to the same of mass flow rate, it can be known that:

$$
\left(q_{\mathrm{m}}\right)_{\mathrm{e}}=\left(q_{\mathrm{m}}\right)_{0}
$$

Substituting Eq. (27) into Eq. (9), the formula becomes:

$$
\left(\frac{Q_{\mathrm{e}}}{Q_{0}}\right) /\left(\frac{f_{\mathrm{e}}}{f_{0}}\right)>1
$$

It can be known from the literature [43]:

$$
\frac{Q_{\mathrm{e}}}{Q_{0}}=\left(\frac{N u_{\mathrm{e}}}{N u_{0}}\right)_{R e}
$$

Based on the Eq. (22) and Eq. (27), it can be known that: 


$$
R e_{\mathrm{e}}=R e_{0}
$$

$$
\frac{f_{\mathrm{e}}}{f_{0}}=\left(\frac{f_{\mathrm{e}}}{f_{0}}\right)_{R e}
$$

Substituting Eq. (29) and (31) into Eq. (28), the formula becomes:

$$
\left(\frac{N u_{\mathrm{e}}}{N u_{0}}\right)_{R e} /\left(\frac{f_{\mathrm{e}}}{f_{0}}\right)_{R e}>1
$$

Eqs. (17), (26) and (32) can be unified in a general expression as follows:

$$
C_{Q, i}=\left(\frac{N u_{\mathrm{e}}}{N u_{0}}\right)_{R e} /\left(\frac{f_{\mathrm{e}}}{f_{0}}\right)_{R e}^{k_{i}}(i=P, \Delta p, V)
$$

where $f_{0}(R e)=c_{1} R e^{\mathrm{m}_{1}} ; N u_{0}(R e)=c_{2} R e^{\mathrm{m}_{2}} ; k_{P}=\frac{\mathrm{m}_{2}}{3+\mathrm{m}_{1}} ; k_{\Delta p}=\frac{\mathrm{m}_{2}-1}{2+\mathrm{m}_{1}} ; k_{V}=1$.

Taking the logarithm of Eq. (33), the formula becomes:

$$
\ln \left(\frac{N u_{\mathrm{e}}}{N u_{0}}\right)_{R e}=b_{i}+k_{i} \ln \left(\frac{f_{\mathrm{e}}}{f_{0}}\right)_{R e}
$$

where $b_{P}=\ln C_{Q, P} ; \quad b_{\Delta p}=\ln C_{Q, \Delta p} ; \quad b_{V}=\ln C_{Q, V} ; \quad-1 \leq \mathrm{m}_{1}<0, \quad 0<\mathrm{m}_{2}<1$.

So it can be obtained that: $\frac{\mathrm{m}_{2}-1}{2+\mathrm{m}_{1}}<0<\frac{\mathrm{m}_{2}}{3+\mathrm{m}_{1}}<1$.

If $\left(\frac{f_{\mathrm{e}}}{f_{0}}\right)_{R e}$ and $\left(\frac{N u_{\mathrm{e}}}{N u_{0}}\right)_{R e}$ are taken as $\mathrm{x}$-coordinate and $\mathrm{y}$-coordinate respectively, then $b_{i}$ represents the intercept of the y-coordinate and $k_{i}$ represents the slope of the straight line. When different strengthening technologies are adopted under the same working conditions, the larger slope indicates the greater exergy efficiency. For the same strengthening technology, the slope $k_{i}$ is the same, then the vertical intercept $b_{i}$ is needed to be compared, and the larger vertical intercept indicates the greater exergy efficiency. Figure 9 is established based on Eq. (34). The $\mathrm{x}$-coordinate indicates the ratio of the frictional resistance coefficient of the enhanced 
tube to that of the circular tube under the same Reynolds number. The y-coordinate indicates the ratio of the Nusselt number of the enhanced tube to that of the circular tube under the same Reynolds number. The straight line passed the point $(1,1)$ when $b_{i}=0$, it indicates that the exergy efficiency of the enhanced tube is the same as that of circular tube under the corresponding conditions. When $b_{i}>0$, it indicates that the exergy efficiency of the enhanced tube is greater than that of circular tube under the corresponding conditions. Oppositely, when $b_{i}<0$, it means that the exergy efficiency of the enhanced tube is lower than that of circular tube under the corresponding conditions. The three straight lines that $\left(q_{\mathrm{m}}\right)_{\mathrm{e}} /\left(q_{\mathrm{m}}\right)_{0}=1 、 P_{\mathrm{e}} / P_{0}=1$ and $\Delta p_{\mathrm{e}} / \Delta p_{0}=1$ are the critical lines of exergy efficiency for the same mass flow rate, pumping power and pressure drop. The three critical lines divide the Figure 9 into four regions named 1, 2, 3, 4 respectively. Region 1 shows that the exergy efficiency of the enhanced tube is lower than that of circular tube under the same pressure drop. Region 2 indicates that the exergy efficiency of the enhanced tube is enhanced under the same pressure drop but it is deteriorated under the same pumping power. Region 3 indicates that the exergy efficiency of the enhanced tube is greater than that of circular tube under the same pumping power but it is lower than that of circular tube under the same mass flow rate. Region 4 indicates that the exergy efficiency of enhanced tube is obviously enhanced under the same mass flow rate. 


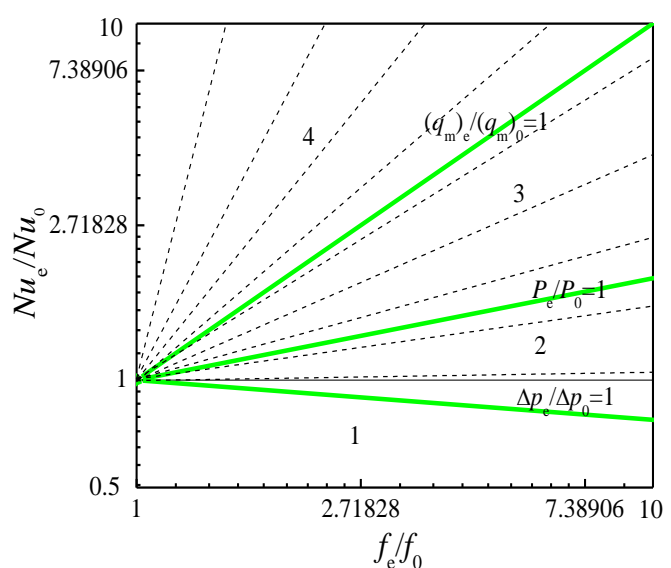

Figure 9 Performance evaluation plot for exergy efficiency

The two critical lines $\left(q_{\mathrm{m}}\right)_{\mathrm{e}} /\left(q_{\mathrm{m}}\right)_{0}=1$ and $P_{\mathrm{e}} / P_{0}=1$ coincide with those in the literature [43], while the critical line $\Delta p_{\mathrm{e}} / \Delta p_{0}=1$ is different from that of literature [43]. Literature [43] studied the energy efficiency evaluation criteria. This shows that the exergy efficiency and energy efficiency are both related and different. Exergy efficiency can express the quality and quantity of energy, while the energy efficiency can only represent the amount of energy.

Figures 10, 11 and 12 are the exergy efficiency analysis plots under the same pressure drop, pumping power and mass flow rate respectively.

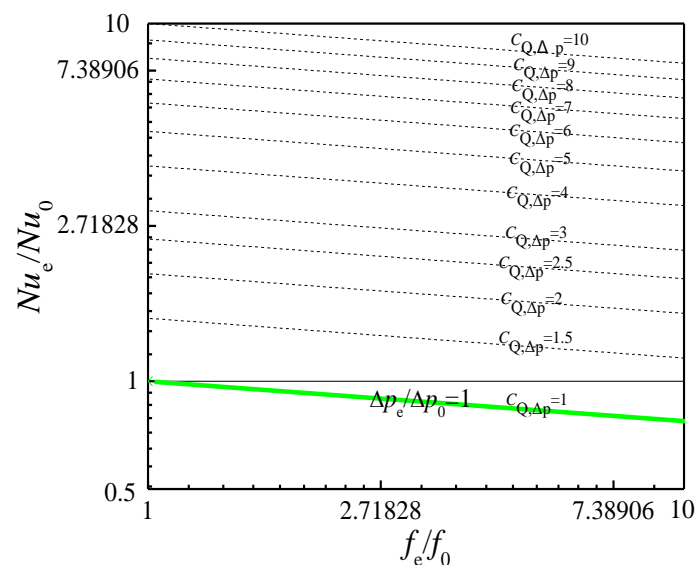

Figure 10 Performance evaluation plot for exergy efficiency under the same pressure drop 


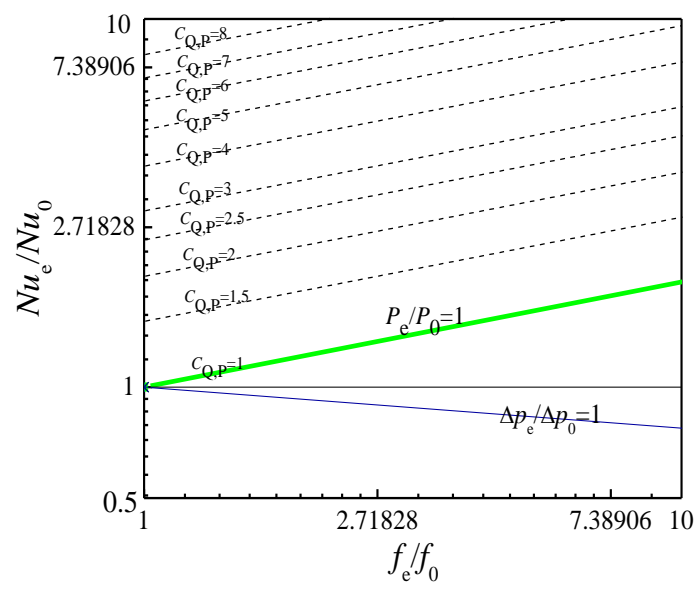

Figure 11 Performance evaluation plot for exergy efficiency under the same pumping power

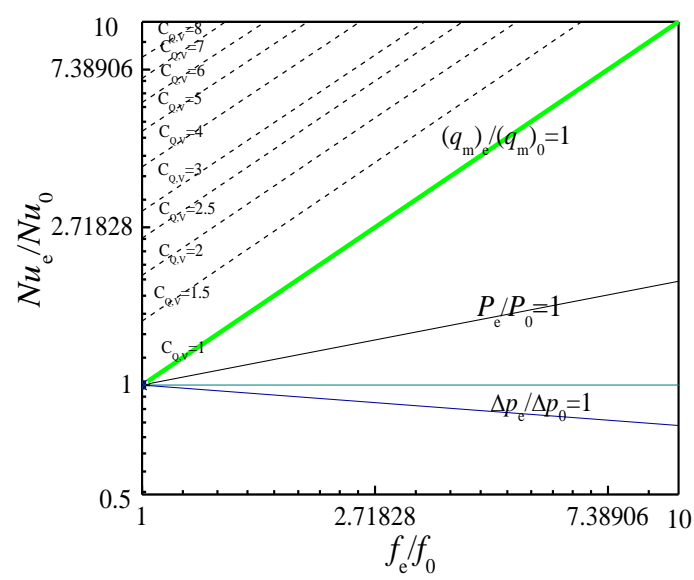

Figure 12 Performance evaluation plot for exergy efficiency under the same mass flow rate

\subsection{Experimental data analysis}

The data analysis step is shown in Figure 13. The meanings of the parameters in the formulas are given in the nomenclature. The thermal conductivity and viscosity of the prepared nanofluids are measured in order to meet the need of data calculation. The results of the measurement can be seen in our published article [33]. The specific heat and density of nanofluids can be solved by the related two-phase suspension formulas (35) and (36). The physical parameters of the $\mathrm{TiO}_{2}$ nanoparticles and deionized water are shown in Table 3. 
480

481

482

483

484

485

486

487

488

489

490

491

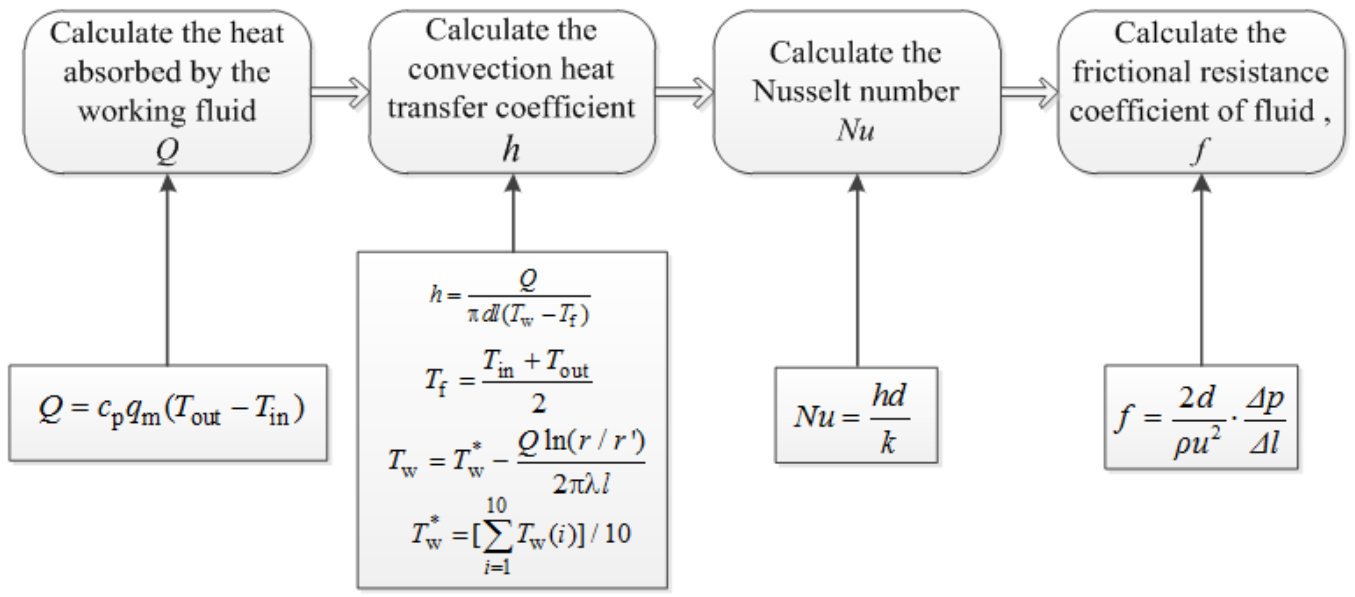

Figure 13 Data analysis step

The formulas of specific heat and density of nanofluids are as follows [45]:

$$
c_{\mathrm{p}}=(1-\varphi) c_{\mathrm{pb}}+\varphi c_{\mathrm{pp}}
$$

$$
\rho_{\mathrm{p}}=(1-\varphi) \rho_{\mathrm{pb}}+\varphi \rho_{\mathrm{pp}}
$$

Gosselin and Silva [46] studied the optimization of thermophysical properties model of nanofluids and found that the computational results are optimal when the model of specific heat Eq. (35) and density Eq. (36) are combined.

The formula of Reynolds number is shown as follows:

$$
\operatorname{Re}=\rho u d / \mu
$$

\begin{tabular}{|c|c|c|c|c|}
\hline Physical properties & $\rho\left(\mathrm{kg} \cdot \mathrm{m}^{-3}\right)$ & $\begin{array}{c}c_{\mathrm{p}} \\
\left(\mathrm{J} \cdot \mathrm{kg}^{-1} \cdot \mathrm{K}^{-1}\right)\end{array}$ & $\mu(\mathrm{Pa} \cdot \mathrm{s})$ & $k\left(\mathrm{~W} \cdot \mathrm{m}^{-1} \cdot \mathrm{K}^{-1}\right)$ \\
\hline $\begin{array}{c}\text { deionized water } \\
{[33]}\end{array}$ & 997.1 & 4179 & 0.001004 & 0.6130 \\
\hline $\begin{array}{c}\mathrm{TiO}_{2} \text { nanoparticles } \\
{[33]}\end{array}$ & 4250 & 686.2 & - & 8.9538 \\
\hline
\end{tabular}

Table 3 Physical parameters of $\mathrm{TiO}_{2}$ nanoparticle and deionized water

\section{Results and discussions}

\subsection{Experimental system validation}

Before testing the heat transfer and flow characteristics of the experimental system, experimental system verification is carried out to ensure its correctness and reliability. 

paper is completely reliable.

503

504

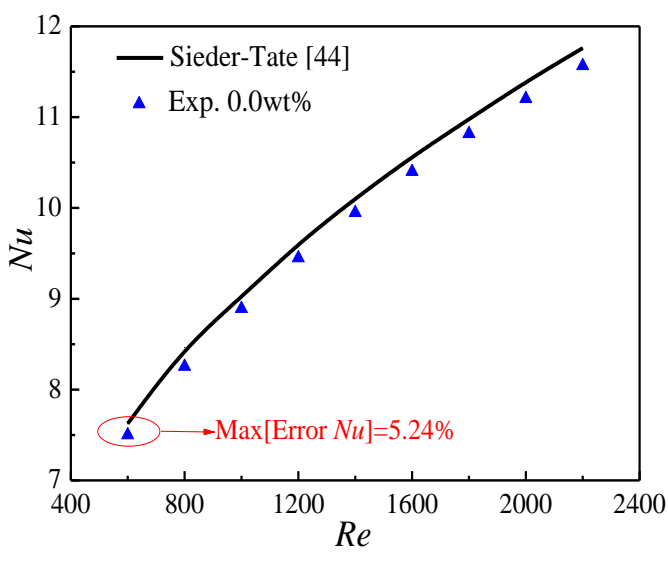

(a)

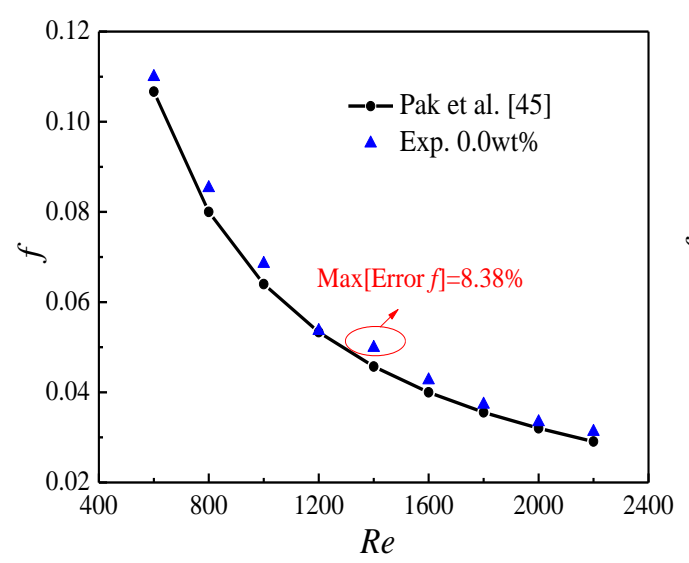

(c)

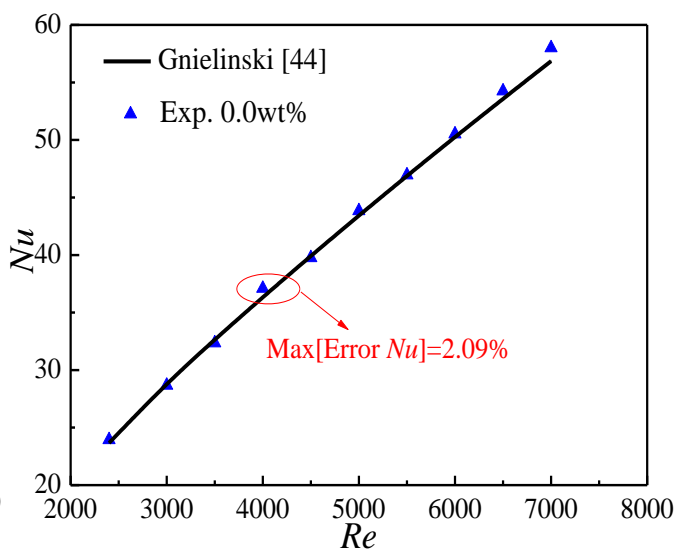

(b)

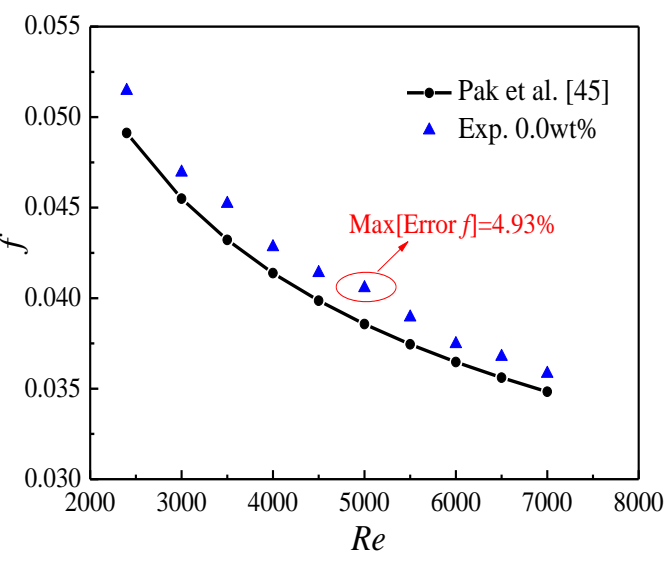

(d)

Figure 14 Heat transfer and flow characteristics of deionized water in a circle tube, (a) $N u$-laminar flow; (b) $N u$-turbulent flow (c) $f$-laminar flow; (d) $f$-turbulent 
512 carry out the uncertainty analysis. There are no the same structure twisted tape in 513 the published literatures compared with the twisted tape in this paper. Hence, the 514 results of fluid in a tube without twisted tape are compared with the results of 515 published literatures. In addition, due to the factor that resistance 516 coefficient corresponds to the pressure drop and there is little data on the pressure 517 drop, in order to compare the results of this manuscript and that of other literatures,

518 the resistance coefficient instead of pressure drop is compared with that of other 519 literatures. The uncertainties of the Nusselt number and flow resistance coefficient 520 in this paper are defined as follows [32]:

$$
\begin{gathered}
\frac{\delta N u}{N u}=\sqrt{\left(\frac{\delta Q}{Q}\right)^{2}+\left(\frac{\delta T}{T}\right)^{2}} \\
\frac{\delta f}{f}=\sqrt{\left(\frac{\delta p}{p}\right)^{2}+\left(\frac{\delta L}{L}\right)^{2}+\left(\frac{\delta q}{q}\right)^{2}}
\end{gathered}
$$

The uncertainties of experimental data are mainly caused by the uncertainties of experimental instruments and measurement errors. The latter can be avoided by on formulas (38) and (39) in this paper are less than 3\%, which shows that the experimental results in this paper are accurate.

Table 4 Parameters and their uncertainties

\begin{tabular}{cccccc}
\hline Parameters & $\begin{array}{c}\text { heat } \\
\text { power }\end{array}$ & temperature & $\begin{array}{c}\text { pressure } \\
\text { transducer }\end{array}$ & length & mass flow rate \\
\hline Uncertainties & $1.0 \%$ & $1.0 \%$ & $0.5 \%$ & $0.1 \%$ & $1.06 \%$ \\
\hline
\end{tabular}


3.3 Experimental results and discussions

After experimental system validation, the heat transfer and flow characteristics of the $\mathrm{TiO}_{2}-\mathrm{H}_{2} \mathrm{O}$ nanofluids with different mass fractions in the circular tube with rotating and static built-in twisted tape are studied respectively.

With the increasing nanoparticle concentration, both density and viscosity increase, hence, it is difficult to confirm the changes of velocity along with the nanoparticle concentration based on equation (37). In order to investigate the relationship between velocity and nanoparticle concentration, Figure 15 presents the changes of velocity with nanoparticle mass fraction under different Reynolds numbers. It can be found that velocity increases with nanoparticle mass fraction. Nanofluids with $\omega=0.1 \%, 0.3 \%$ and $0.5 \%$ can increases the velocity by $3.9 \%, 7.8 \%$ and $13.6 \%$ compared with water respectively.

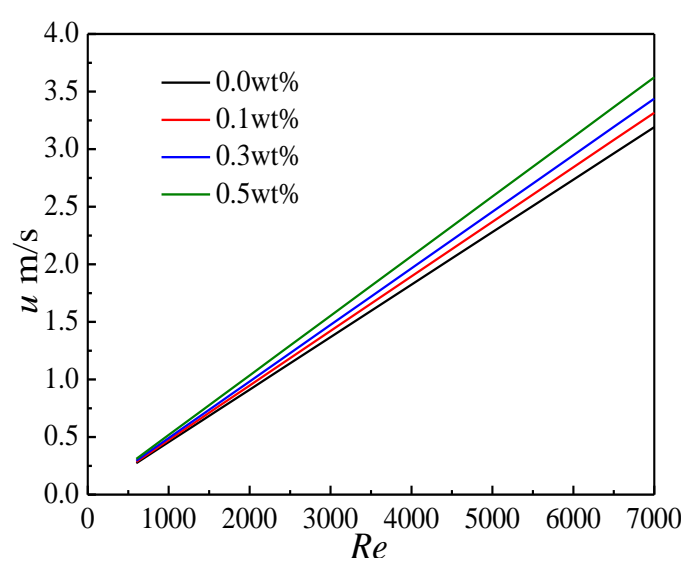

Figure 15 Changes of velocity with nanoparticle mass fraction under different Reynolds numbers

Figure 16 shows the Nusselt number of the $\mathrm{TiO}_{2}-\mathrm{H}_{2} \mathrm{O}$ nanofluids in the circular tube with rotating and static built-in twisted tape. The effects of nanoparticle mass fraction and Reynolds number on heat transfer are also discussed. 


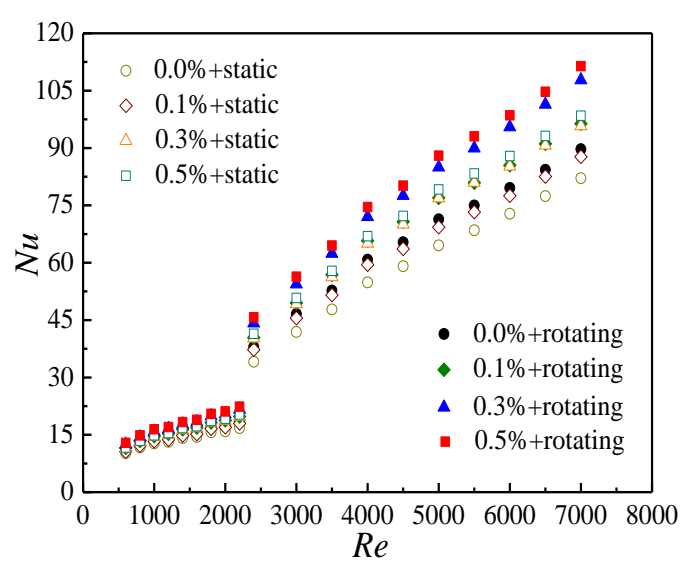

(a)

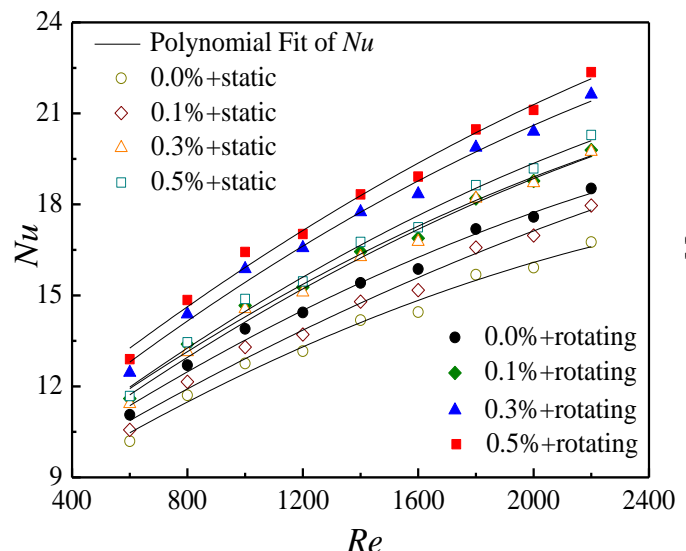

(a-1)

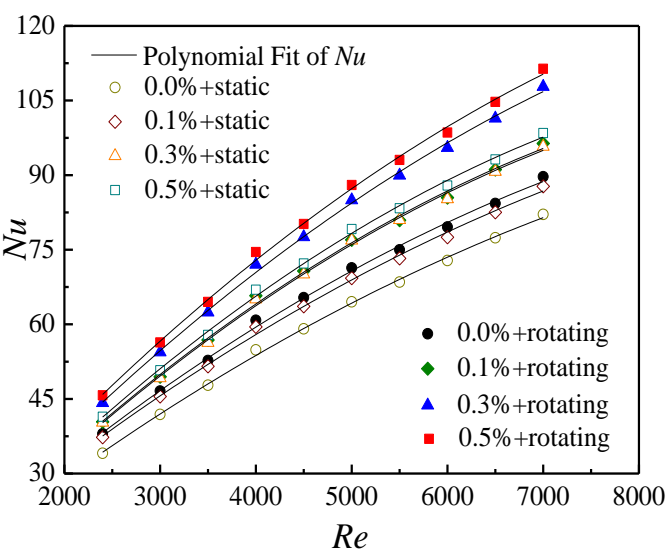

(a-2)

Figure 16 Nusselt numbers of nanofluids, (a) Nusselt numbers at different Reynolds numbers; (a-1) fitted curves at laminar flow; (a-2) fitted curves at turbulent flow

Figure 16 (a) presents that Nusselt number of the tube with built-in rotating twisted tape increases by $13.1 \%$ at best compared with that with static built-in twisted tape at the same nanoparticle mass fraction and Reynolds number. This is because the rotation of twisted tape increases the turbulence of fluid in the tube, destroys the laminar boundary layer to a greater extent, which can improve the heat transfer greatly. It can also be found that the heat transfer of the working medium is improved obviously with the increasing Reynolds numbers. Velocity of working medium increases with the Reynolds numbers and can destroy the laminar boundary layer, which can enhance the heat transfer because of the small thickness 
564 of boundary layer and heat transfer resistance. In addition, it can be found that

565 Nusselt number shows a trend of increasing with the nanoparticle mass fraction,

566 which is due to the high thermal conductivity and Brownian motion of $\mathrm{TiO}_{2}$

567 nanoparticles. In the circular tube with rotating built-in twisted tape, nanofluids

568 with $\omega=0.1 \%, 0.3 \%$ and $0.5 \%$ can improve the heat transfer by $19.3 \%, 31.7 \%$ and

$56936.4 \%$ at best respectively compared with water at the same Reynolds number. Also,

570 in the circular tube with static built-in twisted tape, nanofluids with $\omega=0.1 \%, 0.3 \%$

571 and $0.5 \%$ can improve the heat transfer by $9.4 \%, 19.1 \%$ and $22.7 \%$ at best

572 respectively compared with water at the same Reynolds number.

573 In order to study the relationship between Nusselt number and Reynolds

574 number, Figure $16(\mathrm{a}-1)$ and (a-2) show the fitted curves based on the experimental

575 data. It can be found that polynomial fit curve is more close to the experimental

576 results compared with other kinds of fit curve under the scope of Reynolds numbers

577 in this paper, hence, polynomial fit curve is adopted in this paper. It can be seen that

578 the fitted curves match the experimental data well. The corresponding fitting

579 formula between Nusselt number and Reynolds number shown in formula (40) is

580 given. The constant values of the fitting formula (40) are shown in Table 5.

581 The fitting formula between Nusselt number and Reynolds number is as follows:

$$
N u=\mathrm{A}+\mathrm{B} R e+\mathrm{C} R e^{2}
$$

In order to study the effects of the mass fraction and twisted tape on the heat transfer enhancement, the relative enhancement ratios of heat transfer are discussed 
Table 5 Constants of Eq. (40)

\begin{tabular}{|c|c|c|c|c|c|c|}
\hline $\begin{array}{l}\text { Flow } \\
\text { state }\end{array}$ & $\begin{array}{c}\text { Twisted } \\
\text { tape }\end{array}$ & Constant & $0.00 \%$ & $0.10 \%$ & $0.30 \%$ & $0.50 \%$ \\
\hline \multirow{6}{*}{$\begin{array}{l}\text { Laminar } \\
\text { flow }\end{array}$} & \multirow{3}{*}{ Static } & A & 7.00478 & 7.44475 & 7.5704 & 7.65811 \\
\hline & & B & 0.00631 & 0.00609 & 0.00747 & 0.00778 \\
\hline & & $\mathrm{C}$ & $-8.83 \mathrm{E}-07$ & $-6.25 E-07$ & $-9.13 \mathrm{E}-07$ & $-9.64 \mathrm{E}-07$ \\
\hline & \multirow{3}{*}{ Rotating } & A & 7.61308 & 7.82089 & 8.26426 & 8.71977 \\
\hline & & B & 0.00677 & 0.0074 & 0.00816 & 0.00812 \\
\hline & & $\mathrm{C}$ & $-8.53 \mathrm{E}-07$ & $-9.30 \mathrm{E}-07$ & $-9.93 \mathrm{E}-07$ & $-9.15 \mathrm{E}-07$ \\
\hline \multirow{6}{*}{$\begin{array}{l}\text { Turbulent } \\
\text { flow }\end{array}$} & \multirow{3}{*}{ Static } & $\mathrm{A}$ & -0.96211 & 0.46565 & -4.09629 & -4.5672 \\
\hline & & B & 0.01621 & 0.01708 & 0.02071 & 0.0215 \\
\hline & & $\mathrm{C}$ & $-6.34 \mathrm{E}-07$ & $-6.78 \mathrm{E}-07$ & $-9.36 \mathrm{E}-07$ & $-9.85 \mathrm{E}-07$ \\
\hline & \multirow{3}{*}{ Rotating } & $\mathrm{A}$ & -0.88182 & -3.84289 & -3.4927 & -3.6867 \\
\hline & & B & 0.01813 & 0.02074 & 0.02213 & 0.02296 \\
\hline & & $\mathrm{C}$ & $-7.61 \mathrm{E}-07$ & $-9.38 \mathrm{E}-07$ & $-9.10 \mathrm{E}-07$ & $-9.53 \mathrm{E}-07$ \\
\hline
\end{tabular}

The relative heat transfer enhancement ratio $E$ is defined as follows:

$$
E=\frac{N u}{N u_{\text {water+circular tube }}}
$$

where the subscript "water + circular tube" presents the water in a circular tube.

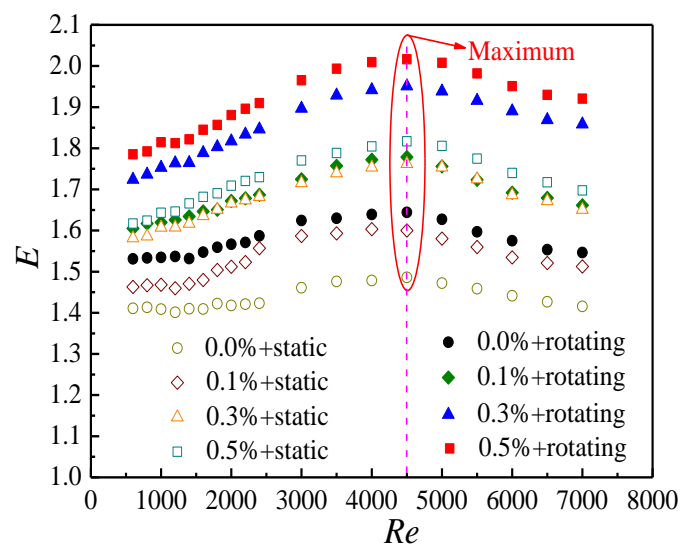

Figure 17 Relative heat transfer enhancement ratios

Figure 17 shows that the heat transfer enhancement ratio firstly increases and then reduces with Reynolds number, and there is a critical Reynolds number $(R e=4500)$ for the maximum value of heat transfer enhancement ratio. It may be due to the fact that at higher Reynolds numbers, the convection is strong and hence, the effect of adding the nanoparticles becomes smaller. The critical Reynolds 

be found that nanofluids coupled with rotating twisted tape in the tube can enhance

599 the convection heat transfer by 53.1-101.6\% compared with water in the circular 600 tube. It can also be found that nanofluids coupled with static twisted tape can 601 enhance the convection heat transfer by $40.1-81.7 \%$ compared with water in the 602 circular tube. Heat transfer enhancement ratio in the tube with rotating twisted tape 603 is greater than that with static twisted tape at the same condition. The reasons for 604 above phenomenon have been explained in Figure 16. the Reynolds number (flow rate) and nanoparticle concentration, and it causes an 607 increase in energy consumption and then reduces the experiment efficiency. Therefore, 608 it is imperative to study the changes of resistance coefficient with Reynolds number 609 and nanoparticle mass fraction. Resistance coefficient is a dimensionless quantity in 610 fluid mechanics. It is used to indicate that the resistance of nanofluids in the tube and 611 it is mainly related to the shape of the tube (twisted tape) and characteristics of 612 nanofluids. The formula of resistance coefficient is shown in Figure 13. Figure 18 613 gives the resistance coefficients of nanofluids at different Reynolds numbers. The 614 values of $0 \%+$ rotating are close to the values of $0.5 \%+$ static at laminar flow and $6150.3 \%+$ static at turbulent flow, and they overlap. It is found that the resistance 616 coefficient shows a decreasing trend with the Reynolds number at laminar and 617 turbulent flow, which can be explained by the resistance coefficient formula in Figure 618 13. The relationship between resistance coefficient and Reynolds number are 
619

620

621

627

628

629

630

631

632

633

634

635

636

637

inversely proportional. In addition, it can be seen that resistance coefficient increases with nanoparticle, which is due to the high viscosity caused by the increasing nanoparticle concentration. The effects of rotating and static twisted tape on the resistance coefficients are also investigated. It can be found that nanofluids with nanoparticle mass fraction $0.5 \%$ in the tube with rotating twisted tape can enhance the resistance coefficients by $31.2 \%$ and $27.0 \%$ at best compared with that with static twisted tape at laminar and turbulent flow respectively, which is due to the more vortexes and turbulence caused by the rotating twisted tape.

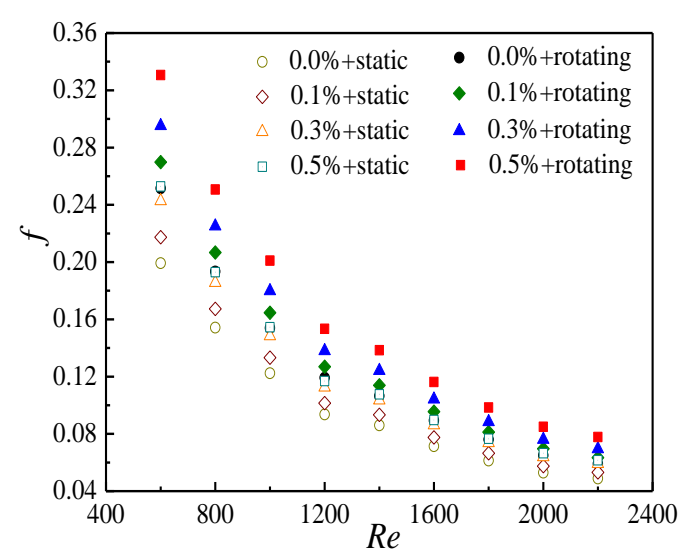

(a)

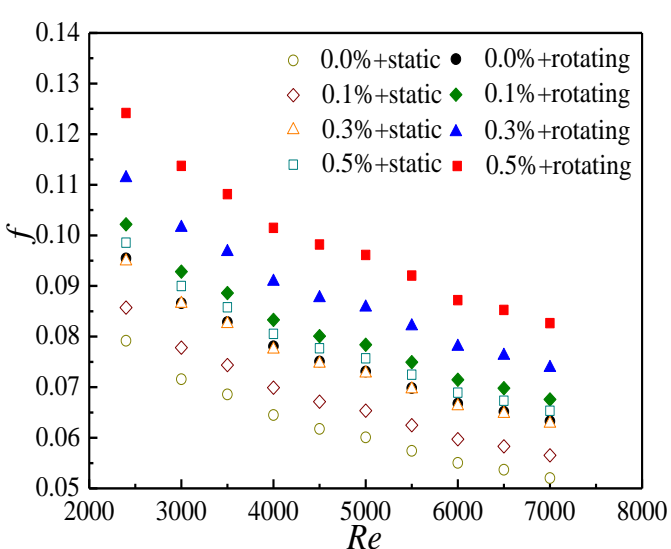

(b)

Figure 18 Resistance coefficients of nanofluids at different Reynolds numbers, (a) laminar flow; (b) turbulent flow

From above studies, it can be seen that the increasing nanoparticle concentration,

Reynolds number and rotating twisted tape can enhance the heat transfer, but they also increase the flow resistance of the experimental system. Hence, it is necessary to investigate the comprehensive evaluation of Nusselt numbers and resistance coefficients. Qiu et al. [47] found that the comprehensive performance index can properly describe these two physical variables. The comprehensive performance index is defined as follows [47]: 
Figure 19 shows the results of the comprehensive performance indexes. It can be

640 found that the comprehensive performance indexes increase at first and then decrease

641 with Reynolds number and can reach a maximum value at $R e=4500$, which is similar

642 to the trend of $E$ in Figure 17. It is found that the comprehensive performance index

643 of nanofluids in the tube with static twisted tape increases with nanoparticle mass

644 fraction, and the range of the comprehensive performance index is 1.157-1.473.

645 However, for the rotating twisted tape, an interesting conclusion which is different

646 from Figure 17 is obtained: $\mathrm{TiO}_{2}-\mathrm{H}_{2} \mathrm{O}$ nanofluids with $0.3 \%$ instead of the highest

647 nanoparticle mass fraction $(\omega=0.5 \%)$ in the tube with rotating twisted tape show the

648 highest comprehensive performance index which can reach 1.519. However,

$649 \mathrm{TiO}_{2}-\mathrm{H}_{2} \mathrm{O}$ nanofluids with $0.5 \%$ in the tube with static twisted tape show the highest

650 comprehensive performance index which can reach 1.473. This is because that the

651 thermal conductivity of $\mathrm{TiO}_{2}-\mathrm{H}_{2} \mathrm{O}$ nanofluids in the tube with rotating twisted tape

652 plays a major role on the comprehensive performance index from $0.0 \%$ to $0.3 \%$, while

653 the viscosity begins to dominate instead of thermal conductivity at higher nanoparticle

654 mass fraction $(\omega>0.3 \%)$. The comprehensive performance index includes two

655 variables: heat transfer characteristics $(\mathrm{Nu})$ and resistance coefficient $(f)$. Thermal

656 conductivity plays a major role in the heat transfer enhancement, and the viscosity

657 plays a major role in the heat transfer deterioration. The phenomenon of Figure 19 can

658 prove the reason. In addition, the published literatures [28, 34] have the similar 
conclusion.

660

661

662

663

664

665

666

667

668

669

670

671

672

673

674

675

676

677

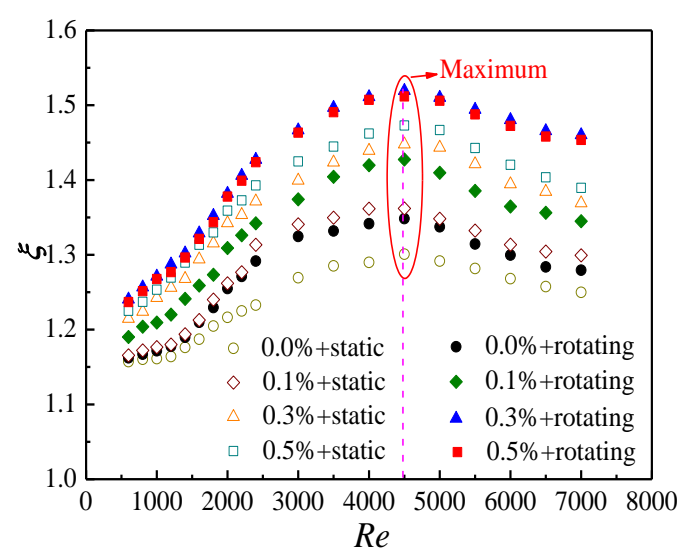

Figure 19 Comprehensive performance indexes

Figure 20 shows the performance evaluation of exergy efficiency under eight different experimental conditions. Figure 21 presents the slopes of experimental data of Figure 20.

It can be seen from Figure 20 and Figure 21 that the exergy efficiency reaches a maximum when $R e=2200$, which is different from the results of the comprehensive performance indexes. For comprehensive performance index in Figure 19, $\mathrm{TiO}_{2}-\mathrm{H}_{2} \mathrm{O}$ nanofluids in the tube with rotating twisted tape show bigger values than that with static twisted tape. In Figure 20 and Figure 21, for water, most of the slopes of the straight lines with rotating twisted tape are larger than that of static twisted tape. However, for nanofluids, most of the slopes of the straight lines with rotating twisted tape are smaller than that of static twisted tape. This means that the rotation of twisted tape can improve but nanofluids deteriorate the exergy efficiency, and the coupling of rotation twisted tape and nanofluids deteriorates the exergy efficiency. This is because that rotation twisted tape makes a greater contribution to heat transfer enhancement ratio than that to resistance coefficient enhancement ratio for exergy efficiency, but nanoparticle mass fraction plays an opposite effect compared with rotation twisted 
682

683

684

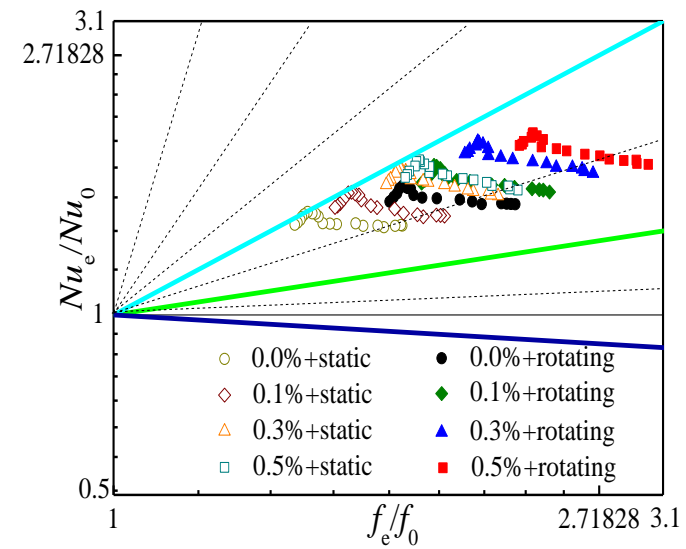

Figure 20 Performance evaluation plot for exergy efficiency

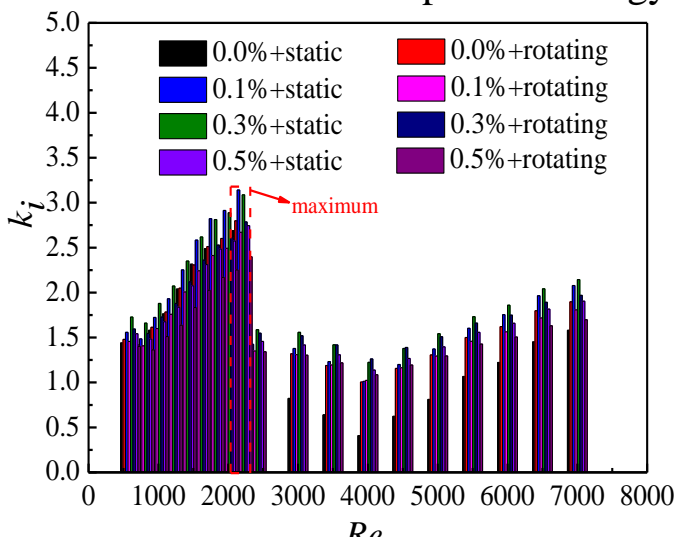

(a)

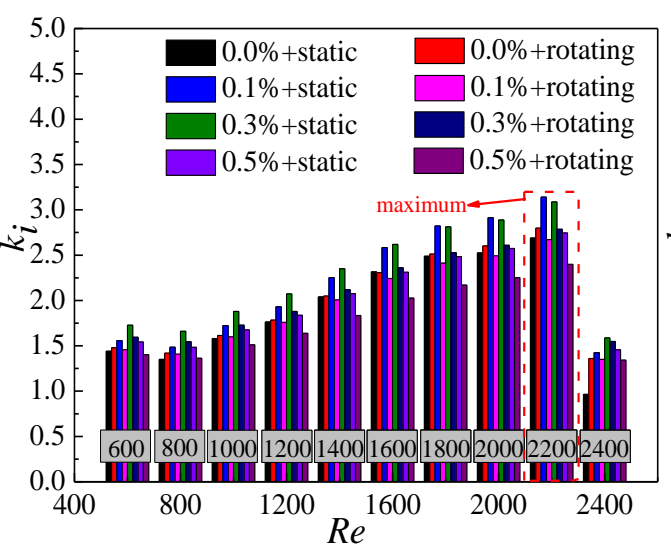

(a-1)

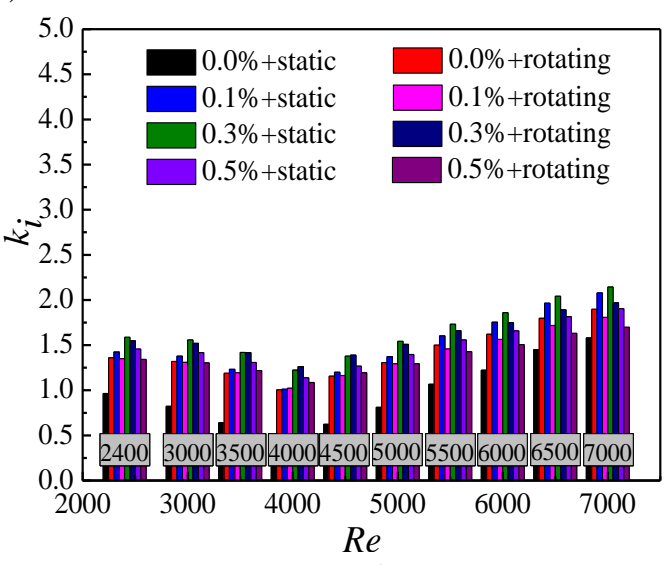

(a-2)

Figure 21 The slopes of experimental data of Figure 20, (a) laminar and turbulent flow, (a-1) laminar flow, (a-2) turbulent flow 


\section{Conclusions}

Heat transfer and flow characteristics of $\mathrm{TiO}_{2}-\mathrm{H}_{2} \mathrm{O}$ nanofluids in a circular tube with rotating and static built-in twisted tapes are experimentally investigated and analyzed by exergy efficiency in this paper. Some conclusions are obtained as follows:

(1) An innovative performance evaluation plot for exergy efficiency is developed in this paper, and it is shown that Region 4 (the highest slope) has the largest exergy efficiency, which can provide some help in exergy efficiency analysis for future new heat exchanger.

(2) $\mathrm{TiO}_{2}-\mathrm{H}_{2} \mathrm{O}$ nanofluids in circular tube with rotating twisted tape shows an excellent enhancement in heat transfer, which can increase the heat transfer by $13.1 \%$ at best compared with nanofluids in circular tube with static built-in twisted tape at the same condition.

(3) $\mathrm{TiO}_{2}-\mathrm{H}_{2} \mathrm{O}$ nanofluids in circular tube with rotating and static built-in twisted tape can strengthen the heat transfer by $53.1-101.6 \%$ and $40.1-81.7 \%$ respectively compared with water in circular tube.

(4) There is the same critical Reynolds number for the maximum values of heat transfer enhancement ratio and comprehensive performance index. The critical Reynolds number is 4500 .

(5) $\mathrm{TiO}_{2}-\mathrm{H}_{2} \mathrm{O}$ nanofluids with $0.3 \%$ instead of the highest nanoparticle mass fraction $(\omega=0.5 \%)$ in the tube with rotating twisted tape show the highest comprehensive performance index which can reach 1.519. 
(6) The coupling of rotation twisted tape and nanofluids deteriorate the exergy

713

714

efficiency compared with static twisted tape. The exergy efficiency of the circular tube with twisted tape is greater than that of circular tube under the same pumping power and pressure drop, while it shows deterioration under the same mass flow rate.

\section{Acknowledgements}

This work is financially supported by "National Natural Science Foundation of China” (Grant No. 51606214).

\section{References}

[1] Huang J, He YR, Wang L, Huang YM, Jiang BC. Bifunctional Au@TiO 2 core-shell nanoparticle films for clean water generation by photocatalysis and solar evaporation. Energy Convers Manage 2017; 132: 452-459.

[2] Chen MJ, He YR, Wang XZ, Hu YW. Complementary enhanced solar thermal conversion performance of core-shell nanoparticles. Appl Energ 2018; 211: $735-742$.

[3] Wang XZ, He YR, Cheng G, Shi L, Liu X, Zhu JQ. Direct vapor generation through localized solar heating via carbon-nanotube nanofluid, Energy Convers Manage 2016; 130: 176-183.

[4] Liu XL, Xuan YM. Full-spectrum volumetric solar thermal conversion via photonic nanofluids. Nanoscale 2017; 9(39): 14854-14860.

[5] Liu XL, Xuan YM. Defects-assisted solar absorption of plasmonic nanoshell-based nanofluids. Sol Energy 2017; 146: 503-510.

[6] Xuan YM, Li Q. Heat transfer enhancement of nanofluids. Int J Heat Fluid Flow 
2000; 21(1): 58-64.

[7] Oztop HF, Abu-Nada E. Numerical study of natural convection in partially heated rectangular enclosures filled with nanofluids. Int J Heat Fluid Flow 2008; 29(5): 1326-1336.

[8] Heris SZ, Esfahany MN, Etemad SG. Experimental investigation of convective heat transfer of $\mathrm{Al}_{2} \mathrm{O}_{3}$ /water nanofluid in circular tube. Int $\mathrm{J}$ Heat Fluid Flow 2007; 28(2): 203-210.

[9] Li HR, Wang L, He YR, Hu YW, Zhu JQ, Jiang BC. Experimental investigation investigation of thermal conductivity and viscosity of ethylene glycol based $\mathrm{ZnO}$ nanofluids. Appl Therm Eng. 2014; 88: 363-368.

[10]Li HR, He YR, Hu YW, Jiang BC, Huang YM. Thermophysical and natural convection characteristics of ethylene glycol and water mixture based $\mathrm{ZnO}$ nanofluids. Int J Heat Mass Transfer 2015; 91: 385-389.

[11]Fu R, Yan YY. The Effect of particle disaggregation on viscosity of $\mathrm{Fe}_{3} \mathrm{O}_{4}$ ethylene glycol-water nanofluid. J Nanofluids 2018; 7(3): 413-419.

[12]Hong JJ, Liu S, Yan YY, Glover P. Experimental measurement of dynamic concentration of nanofluid in laminar flow. Exp Therm Fluid Sci 2017; 88: 483-489.

[13] Sheremet MA, Pop I, Mahian O. Natural convection in an inclined cavity with time-periodic temperature boundary conditions using nanofluids: Application in solar collectors. Int J Heat Mass Transfer 2018; 116: 751-761.

[14] Sheremet MA, Pop I, Ishak A. Time-dependent natural convection of micropolar 
fluid in a wavy triangular cavity. Int J Heat Mass Transfer 2017; 105: 610-622.

757

[15] Sheremet MA, Oztop HF, Pop I, Al-Salem K. MHD free convection in a wavy open porous tall cavity filled with nanofluids under an effect of corner heater. Int J Heat Mass Transfer 2016; 103: 955-964.

[16] Sheikholeslami M, Seyednezhad M. Simulation of nanofluid flow and natural convection in a porous media under the influence of electric field using CVFEM. Int J Heat Mass Transfer 2018; 120: 772-781.

[17] Sheikholeslami M, Shehzad SA. Magnetohydrodynamic nanofluid convection in a porous enclosure considering heat flux boundary condition. Int $\mathbf{J}$ Heat Mass Transfer 2017; 106: 1261-1269.

[18] Sheikholeslami M, Shehzad SA. CVFEM for influence of external magnetic source on $\mathrm{Fe}_{3} \mathrm{O}_{4}-\mathrm{H}_{2} \mathrm{O}$ nanofluid behavior in a permeable cavity considering shape effect. Int J Heat Mass Transfer 2017; 115: 180-191.

[19]Rudyak VY, Krasnolutskii SL. Dependence of the viscosity of nanofluids on nanoparticle size and material. Phys Lett A 2014; 378: 1845-1849.

[20]Pendyala R, Ilyas SU, Lian RL, Marneni N. CFD Analysis of heat transfer performance of nanofluids in distributor transformer. Procedia Eng 2016; 148 : 1162-1169.

[21]Ilyas SU, Pendyala R, Narahari M, Susin L. Stability, rheology and thermal analysis of functionalized alumina-thermal oil-based nanofluids for advanced cooling systems. Energy Convers Manage 2017; 142: 215-219.

[22]Kouloulias K, Sergis A, Hardalupas Y. Sedimentation in nanofluids during a 
natural convection experiment. Int J Heat Mass Transfer 2016; 101: 1193-1203.

[23]Qi C, Wang GQ, Ma YF, Guo LX. Experimental research on stability and natural convection of $\mathrm{TiO}_{2}$-water nanofluid in enclosures with different rotation angles. Nanoscale Res Lett 2017; 12(1): 396-410.

[24]Qi C, Yang LY, Wang GQ. Numerical study on convective heat transfer enhancement in horizontal rectangle enclosures filled with $\mathrm{Ag}-\mathrm{Ga}$ nanofluid. Nanoscale Res Lett 2017; 12(1): 326-335.

[25]Qi C, Wang GQ, Yang LY, Wan YL, Rao ZH. Two-phase lattice Boltzmann simulation of the effects of base fluid and nanoparticle size on natural convection heat transfer of nanofluid. Int J Heat Mass Transfer 2017; 105: 664-672.

[26]Qi C, Liang L, Rao ZH. Study on the flow and heat transfer of liquid metal base nanofluid with different nanoparticle radiuses based on two-phase lattice Boltzmann method. Int J Heat Mass Transfer 2016; 94: 316-326.

[27]Qi C, Wan YL, Liang L, Rao ZH, Li YM. Numerical and experimental investigation into the effects of nanoparticle mass fraction and bubble size on boiling heat transfer of $\mathrm{TiO}_{2}$-water nanofluid. ASME J Heat Transfer 2016; 138(8): 081503.

[28]Qi C, Hu JD, Liu MN, Guo LX, Rao ZH. Experimental study on thermo-hydraulic performances of CPU cooled by nanofluids. Energy Convers Manage 2017; 153: 557-565.

[29] Shahril SM, Quadir GA, Amin NAM, Badruddin IA. Numerical investigation on the thermohydraulic performance of a shell-and-double concentric tube heat 

Part A, 2017; 71: 215-231.

D. Experimental study on the heat transfer and flow characteristics of nanofluids in the built-in twisted belt external thread tubes. Int $\mathbf{J}$ Heat Mass Transfer 2017; 107: 712-722.

[31] Sun B, Zhang ZM, Yang D. Improved heat transfer and flow resistance achieved 
021015.

823

[37]Khalkhali H, Faghri A, Zuo ZJ. Entropy generation in a heat pipe system. Appl Therm Eng 1999; 19(10): 1027-1043.

[38]Haddad OM, Alkam MK, Khasawneh MT. Entropy generation due to laminar forced convection in the entrance region of a concentric annulus. Energy 2004; 29(1): $35-55$

[39]Ploumen PJ, Janssen F. Through exergy approach to more efficient processes. Int J Thermodyn 2001; 4(2): 119-125

[40]Gutowski T, Dahmus J, Thiriez A, Branham M, Jones A. A thermodynamic characterization of manufacturing processes. IEEE Int Symp Electron Environ 2007; 5(1): 7-10

[41]Modarresi A, Kravanja P, Friedl A. Pinch and exergy analysis of lignocellulosic ethanol, biomethane, heat and power production from straw. Appl Therm Eng 2012; 43: 20-8.

[42]Zhu MS. Exergy analysis of energy systems, Beijing: Tsinghua University Press; 1988

[43]Fan JF, Ding WK, Zhang JF, He YL, Tao WQ. A performance evaluation plot of enhanced heat transfer techniques oriented for energy-saving. Int J Heat Mass Transfer 2009; 52(2): 33-44.

[44] Yang SM, Tao WQ. Heat Transfer, 4th ed. Beijing: Higher Education Press; 2012. [45]Pak BC, Cho YI. Hydrodynamic and heat transfer study of dispersed fluids with submicron metallic oxide particles. Exp Heat Transfer 1998; 11(2): 151-170. 
844 [46]Gosselin L, Silva AK. Combined heat transfer and power dissipation optimization 845 of nanofluid flow. Appl Phys Lett 2004; 85(18): 4160-4162.

846 [47]Qiu L, Deng HW, Sun JN. Pressure drop and heat transfer in rotating smooth 847 square U-duct under high rotation numbers. Heat Mass Transfer 2013; 66: 848 $543-552$. 